\title{
Unravelling the potential of nitric acid as a surface modifier for improving the hemocompatibility of metallocene polyethylene for blood contacting devices
}

Muthu Vignesh Vellayappan, Saravana Kumar Jaganathan, Ida Idayu Muhamad

Design of blood compatible surfaces is obligatory to minimize platelet surface interactions and improve the thromboresistance of foreign surfaces when they are utilized as biomaterials particularly for blood contacting devices. Pure metallocene polyethylene (MPE) and nitric acid (HNO3) treated MPE antithrombogenicity and hydrophilicity were investigated. The contact angle of the MPE treated with HNO3 decreased. Surface of MPE and $\mathrm{HNO}$ treated $\mathrm{mPE}$ investigated with FTIR revealed no major changes in its functional groups. 3D Hirox digital microscopy, SEM and AFM images show increased porosity and surface roughness. Blood coagulation assays prothrombin time (PT) and activated partial thromboplastin time (APTT) were delayed significantly $(\mathrm{P}<0.05)$ for HNO3 treated $\mathrm{mPE}$. Hemolysis assay and platelet adhesion of the treated surface resulted in the lysis of red blood cells and platelet adherence, respectively indicating improved hemocompatibility of HNO3 treated mPE. To determine that HNO3 does not deteriorate elastic modulus of $\mathrm{mPE}$, the elastic modulus of mPE and HNO3 treated mPE was compared and the result shows no significant difference. Hence, the overall observation suggests that the novel $\mathrm{HNO} 3$ treated mPE may hold great promises to be exploited for blood contacting devices like grafts, catheters, and etc. 
1 Unravelling the potential of nitric acid as a surface modifier for improving the

4 Muthu Vignesh Vellayappan ${ }^{1}$, Saravana Kumar Jaganathan ${ }^{1 *}$, Ida Idayu Muhamad ${ }^{1}$

$5 \quad{ }^{1}$ IJN-UTM Cardiovascular Engineering Centre, Faculty of Biosciences and Medical Engineering,

6 Universiti Teknologi Malaysia, Johor Bahru 81310, Malaysia

7 *Corresponding author: Dr Saravana Kumar Jaganathan, IJN-UTM Cardiovascular

8 Engineering Centre, Faculty of Biosciences and Medical Engineering, University Teknologi

9 Malaysia, Johor Bahru 81310, Malaysia; Email: jaganathaniitkgp@gmail.com;Tel; 00607-

10 5558548; Fax: 07-5558553

11 Abstract

12 Design of blood compatible surfaces is obligatory to minimize platelet surface 13 interactions and improve the thromboresistance of foreign surfaces when they are utilized as 14 biomaterials particularly for blood contacting devices. Pure metallocene polyethylene (mPE) and 15 nitric acid $\left(\mathrm{HNO}_{3}\right)$ treated $\mathrm{mPE}$ antithrombogenicity and hydrophilicity were investigated. The 16 contact angle of the mPE treated with $\mathrm{HNO}_{3}$ decreased. Surface of $\mathrm{mPE}$ and $\mathrm{HNO}_{3}$ treated mPE 17 investigated with FTIR revealed no major changes in its functional groups. 3D Hirox digital 18 microscopy, SEM and AFM images show increased porosity and surface roughness. Blood 19 coagulation assays prothrombin time (PT) and activated partial thromboplastin time (APTT) were 20 delayed significantly $(\mathrm{P}<0.05)$ for $\mathrm{HNO}_{3}$ treated $\mathrm{mPE}$. Hemolysis assay and platelet adhesion of 21 the treated surface resulted in reduced lysis of red blood cells and platelet adherence, respectively 22 indicating improved hemocompatibility of $\mathrm{HNO}_{3}$ treated mPE. To determine that $\mathrm{HNO}_{3}$ does not 23 deteriorate elastic modulus of mPE, the elastic modulus of $\mathrm{mPE}$ and $\mathrm{HNO}_{3}$ treated mPE was 24 compared and the result shows no notable difference. Hence, the overall observation suggests that 25 the novel $\mathrm{HNO}_{3}$ treated mPE may hold great promises to be exploited for blood contacting 26 devices like heart valves, stents and etc. 
Introduction

The surface modification of biomaterials is a process of modifying its surface properties

31 by changing its inherent physical, chemical or biological properties to possess desirable

32 characteristics (John et al, 2015). Generally, the surface modification of biomaterials can be done

33 via different techniques for the biocompatibility enhancement, which is the cornerstone property

34 required whilst selecting a blood contacting device (Jaganathan et al, 2014a; Vellayappan et al,

35 2015a). There is a wide range of blood contacting devices available nowadays like grafts,

36 catheters, hemodialysis, bypass/extracorporeal membrane oxygenation, and ventricular assist

37 devices (VADs). Even though there is a widespread need for blood contacting devices, the

38 formation of blood coagulation as well as commencement of thrombotic events whilst the

39 biomaterial comes in contact with the blood, remains as a daunting challenge for researchers to

40 decipher (Velayyappan et al., 2015). A recent statistic shows that $65-88 \%$ of aortic repair

41 procedures performed in the US are being replaced with endovascular grafts and the thrombus

42 formation in aortic side branches often leads to ischemia (Thompson, 2013). Another clinical

43 study dictates that thrombus formation on the catheter surface in $50 \%$ of patients undergoing

44 diagnostic angiography (Formanek G \& Frech RS., 1970). Moreover, thrombosis is found to be

45 the precipitating event in $30-40 \%$ of central venous catheter malfunctions (Vascular Access,

46 2006). Thus, prevention of thrombotic deposition and occlusion, triggered by the activation of the

47 coagulation cascade and platelets, is a mandatory property which the implanted blood contacting

48 devices should possess before it is recommended for clinical trials.

The advent of latest technology has paved the way for the discovery of novel polymers

50 like metallocene which is a new class of polyolefins with superior performance characteristics

51 like improved toughness, sealability, clarity, and elasticity. Metallocene is made up of two

52 cyclopentadienyl anions $(\mathrm{Cp}$,$) which are attached to a metal center (\mathrm{M})$ with an oxidation state II,

53 hence resulting in a general formula $\mathrm{M}\left(\mathrm{C}_{5} \mathrm{H}_{5}\right)_{2}$ (Kealy TJ \& Pauson PL, 1951). The metallocene 
54 polyethylene (mPE) is one of the versatile polymers. The $\mathrm{mPE}$ has wide spectrum of applications

55 in disposable bags, storage bottles, blood bags, and syringe tubes. Albeit mPE has an excellent

56 permeability to oxygen and functions as an effective barricade towards ammonia and water, yet

57 mPE poor blood compatibility hampers it from being used for blood contacting devices

58 (Mohandas et al, 2013). Thus, different works were done for enhancing the blood compatibility of

$59 \mathrm{mPE}$ recently to promote it for various biomedical applications.

60 In our group, we are exploring several modification techniques to improve the blood

61 compatibility of mPE. Recently, Mohandas et al., utilized microwave radiation for surface

62 modification of the mPE to improve its blood compatibility (Mohandas et al, 2013). Furthermore,

63 the effect of hydrochloric $(\mathrm{HCl})$ acid treatment on the metallocene polyethylene mPE depicted an

64 enhanced blood compatibility of mPE compared to the untreated mPE sample (Jaganathan et al,

65 2014).

66 Since the $\mathrm{HCl}$ etching effect on $\mathrm{mPE}$ yielded good results, it further motivated us to find

67 other available substitutes which are cost effective and easily available for improving the blood

68 compatibility of mPE. Thus, being a very strong acid and oxidizing agent, we have selected

$69 \mathrm{HNO}_{3}$ for improving the blood compatibility of mPE. In a work done utilizing $\mathrm{HNO}_{3}$ by Moreno-

70 Castilla et al., dictates that the $\mathrm{HNO}_{3}$ treatment affects the surface area of activated carbons and

71 their porosity the most compared to the other treatments like hydrogen peroxide, and ammonium

72 peroxydisulfate treatments (Moreno-Castilla et al, 1995). Moreover, Dong et al., demonstrated

73 the $\mathrm{HNO}_{3}$ oxidation treatment on CNT modifies the CNTs physical and chemical properties

74 resulting in improved CNTs biocompatibility (Dong et al, 2012). For the first time the effect of

$75 \mathrm{HNO}_{3}$ treatment on mPE is documented in this work. Furthermore, the present study is done to

76 ascertain the modifications induced in $\mathrm{mPE}$ and its impact on the blood compatibility of the

$77 \quad \mathrm{HNO}_{3}$ treated mPE samples.

78 Materials and Methods 


\section{Ethics Statement}

The blood coagulation assays were carried out in India and the characterization tests were

81 done in Malaysia. Prior to blood procurement, the written consent form was given to the healthy

82 volunteers. They read the benefits and risks of participation before expressing his/her willingness

83 by signing the form. All protocols of blood procurement and consent procedure were approved by

84 the Pacheri Sri Nallathangal Amman (PSNA) College of Engineering and Technology Ethical

85 Committee of Dindigul with an approved IRB number: H30114. Later, the blood was extracted

86 via venipuncture from aspirin-free healthy adult human donor and it is prevented from

87 coagulation with trisodium citrate at a volumetric ratio of 9:1. Newly prepared platelet rich

88 plasma (PRP) was acquired from the Dindigul Blood Bank, Dindigul, India.

\section{Sample Preparation and Acid Treatment}

90 Initially, two mPE films of dimensions $10 \mathrm{~cm} \times 10 \mathrm{~cm}$ were cut into two samples with a

91 size of $1 \mathrm{~cm} \times 1 \mathrm{~cm}$. Then the samples were washed with $70 \%$ ethanol and distilled water prior

92 subjecting it to $\mathrm{HNO}_{3}$ treatment. Then, 8- $10 \mathrm{ml}$ of concentrated $\mathrm{HNO}_{3}$ with molarity of $15.9 \mathrm{M}$

93 was poured into petri dish which contains the square shaped sheets of $\mathrm{mPE}$. The acid and sample

94 containing dishes were later placed on the rocking shaker which moves at a constant speed.

95 Moreover, in this work mPE sample were subjected to $\mathrm{HNO}_{3}$ exposure for the different time

96 durations. From that, the optimized timings were selected by observing surface changes with an

97 optical microscope at 40x. The samples subjected for a lesser duration didn't confer notable

98 surface modifications when compared with control, however, during 30 minutes of exposure

99 significant change in the surface of mPE was observed. While subjecting samples for a prolonged

100 period, changes noted, were not significant compared to 60 minutes treated sample. Thus, for

101 characterization studies, 30 minutes and 60 minutes treated samples alone were considered. Once

102 the acid treatment was done, the samples were washed in distilled water and dried at room

103 temperature overnight before performing any characterization tests. Whilst preparing the samples 
104 for blood compatibility tests, samples were kept in a beaker with physiological saline and then in

105 a rotary shaker overnight at $37^{\circ} \mathrm{C}$ to remove the acid present on the surface of the polymer.

106 The scheme of the experiments performed was shown in Fig.1.

107 Characterization of the Samples

108 Contact Angle Measurement

109 The hydrophilicity tendency of the polymer was determined using Dynamic Contact

110 Angle Analyzer (FTA200-First Ten Angstroms). Here, water droplet was placed on the surface

111 of the sample. Water droplet of $1 \mu \mathrm{L}$ was used and the photographs were taken in the ultra-fast

112 mode within 30 seconds. The degree of the angle formed is determined using computer interfaced

113 software. The contact angles were recorded and analyzed for the samples which are untreated

$114 \mathrm{mPE}, 30$ minutes and 60 minutes $\mathrm{HNO}_{3}$ exposed samples $(n=3)$.

\section{Attenuated Total Reflectance Fourier Transfer Infrared Spectroscopy (ATR-FTIR)}

116 ATR-FTIR equipment NEXUS- 870 model spectrophotometer was utilized have

117 additional features such as extended beam splitter, two light sources, and middle band MCT

118 detectors with various sampling options. This was used for the purpose of analyzing the chemical

119 compositions or functional groups present within the polymer. There are three samples present in

120 the study, which are untreated mPE, 30 minutes and 60 minutes $\mathrm{HNO}_{3}$ treated mPE samples. All

121 these samples were studied using this ATR-FTIR.

\section{3D-Hirox Digital Microscope}

123 The latest 3D-Hirox digital microscope model (KH-8700) was used to determine the

124 formation of pits and pores of the samples. The 3D-Hirox digital microscopy images are very

125 useful in determining the morphological structure of samples to determine whether the sample

126 has pores or it has an even surface. There are two types of images which are obtained from 3D-

127 Hirox digital microscopy either with or without profilometry line. The surface morphology of

$1281 \mathrm{~cm} \times 1 \mathrm{~cm}$ of $\mathrm{mPE}$ and $\mathrm{HNO}_{3}$ treated mPE sample was assessed at an area of approximately 
$1295757 \mu^{2}$ at a magnification of $500 \mathrm{X}$. The same as white light confocal profilometry, in-focus and

130 3D images were obtained using this 3D microscope. Slices of the image were captured at

131 different heights acquired for the surface topography analysis (Pereira et la, 2013). Maximum of

132 three profiling lines is chosen as the profiling value of the each sample. Each point in $\mathrm{X}, \mathrm{Y}$ and $\mathrm{Z}$

133 axes of the profiling line is measured and their values can be exported in excel sheet to represent

134 the height of the pits in the sample. Data processing was performed using the in-build 3D

135 profilometry software. Images were recorded at standard 1,200 to 1,600 pixel resolution.

\section{Scanning Electron Microscope}

137 The surface microstructure of the samples can be critically analyzed in detail by using

138 SEM. The SEM which is utilized to study the polymeric samples was JEOL JSM5800 SEM with

139 OXFORD ISI 300 EDS X-ray Microanalysis System. Untreated mPE, 30 minutes and 60 minutes

$140 \mathrm{HNO}_{3}$ treated mPE underwent gold sputtering and then been studied using SEM at a 141 magnification of $1500 x$.

\section{Atomic Force Microscopy}

144 The surface roughness of the samples can be determined with the help of AFM. The AFM 145 model used to analyze the samples is SPA300HV with a scan rate of $1.502 \mathrm{~Hz}$ in tapping mode.

146 Here, the surface morphology of mPE, 30 minutes and 60 minutes $\mathrm{HNO}_{3}$ treated mPE sample 147 was measured by AFM in contact mode on a $10 \times 10 \mu \mathrm{m}^{2}$ area, and the mean average surface 148 roughness $(\mathrm{Ra})$ and 3D pictographic view is obtained. Each AFM image was analyzed in terms of

$149 \mathrm{Ra}$ (Pelagade et al, 2012). The surface roughness is calculated using the software SPIWin.

\section{Tensile Testing}

151 The tensile strength was tested using ZWICK Universal Tester (Z010, Germany) at a gage

152 length of $15 \mathrm{~mm}$ and a speed of $10 \mathrm{~mm}^{-1}$ for the untreated mPE, 30 minutes and 60 minutes 
$153 \mathrm{HNO}_{3}$ treated mPE specimens at a load cell capacity of $100 \mathrm{~N}$ with a sample thickness of $1 \mathrm{~mm}$.

154 The reported tensile moduli is represented as average results of five tests.

\section{Blood Coagulation Assays}

156 Prothrombin Time (PT)

157 Prothrombin time is a valuable indicator to find the prohibition of extrinsic pathway.

158 Platelet poor plasma (PPP) $\left(100 \mu \mathrm{L}\right.$ at $\left.37^{\circ} \mathrm{C}\right)$ was applied on untreated and treated polymer

159 surface with NaCl-thromboplastin (Factor III, $100 \mathrm{~mL}$, Sigma) which contains Ca2+ ions. The

160 time consumed for the formation fibrin clot was assessed with the help of a stopwatch and a steel

161 hook $(n=3)$ (Amarnath LP, Srinivas A and Ramamurthi A et al, 2006).

162 Activated Partial Thromboplastin Time (APTT)

163 APTT is utilized for studying the propensity of the blood to coagulate via intrinsic

164 pathway and to determine the effect of biomaterial on delaying the process. Platelet poor plasma $165\left(100 \mu \mathrm{L}\right.$ at $\left.37^{\circ} \mathrm{C}\right)$ is incubated in prior with substrates at $37^{\circ} \mathrm{C}$ and followed by its activation by 166 adding rabbit brain cephalin $\left(100 \mu \mathrm{L} 37^{\circ} \mathrm{C}\right)$. Later, the samples were incubated at $37^{\circ} \mathrm{C}$ for 5 167 minutes and followed by incubation with calcium chloride $(0.025 \mathrm{M})$. Inclusion of $\mathrm{CaCl}_{2}$ triggers

168 the clotting process. The time taken from the inclusion of $\mathrm{CaCl} 2$ up to clot formation is recorded 169 as the activated partial thromboplastin time (APTT) $(n=3)$ (Amarnath LP, Srinivas A and 170 Ramamurthi A et al, 2006).

171 Hemolysis Assay

$172 \mathrm{The}_{\mathrm{HNO}}$ treated (30 minutes and 60 minutes) and untreated samples were equilibrated 173 with physiologic saline $\left(0.9 \% \mathrm{w} / \mathrm{v} ; 37^{\circ} \mathrm{C}, 30\right.$ minutes $)$ followed by its incubation with $3 \mathrm{~mL}$ 174 aliquots of citrated blood diluted with saline ( $4: 5$ ratios by volume). This mixture of blood and 175 distilled water was prepared at a ratio of 4: 5 by volume to result in comprehensive hemolysis 176 which was used as the positive control. Physiological saline solution was utilized as negative 
177 control which produces no coloration. The samples were subjected to incubation in their

178 respective mixtures $\left(60\right.$ minutes, $\left.37^{\circ} \mathrm{C}\right)$. These mixtures were later centrifuged and their

179 absorbance of clear supernatant was determined at $542 \mathrm{~nm}$. The absorbance of positive control

180 was normalized to $100 \%$ and the absorbance of both the samples was ascertained as a percentage

181 of hemolysis whilst comparing it with positive control $(n=3)$ (Amarnath LP, Srinivas A and

182 Ramamurthi A et al, 2006).

183 Platelet Adhesion Assay

184 The mPE samples were subjected to $\mathrm{HNO}_{3}$ exposure for 30 minutes and 60 minutes, later

185 incubated along with physiological saline $\left(0.9 \% \mathrm{w} / \mathrm{v} ; 37^{\circ} \mathrm{C}, 30\right.$ minutes $)$. This is kept on the rotary 186 shaker for an hour to wash of the acid residues on the surface of the polymer. This is followed by

187 immersing of untreated mPE, 30 minutes and 60 minutes $\mathrm{HNO}_{3}$ treated mPE samples in $1 \mathrm{~mL}$

188 fresh PRP and the incubation was maintained at $37^{\circ} \mathrm{C}$ for an hour. PRP was poured off and the 189 membranes were rinsed in physiologic saline and dried. Ultimately, the samples were viewed

190 using the microscope $(n=3)$. The polymer surface was photographed and platelet count was 191 determined on a region with a 40x magnification (Amarnath LP, Srinivas A and Ramamurthi A et 192 al, 2006).

\section{Statistical Analyses}

194 All experiments were conducted thrice independently. One-way ANOVA was done to 195 determine statistical significance. The results obtained from all experiments are expressed as 196 mean \pm SD. In case of qualitative experiments, a representative of three images is shown.

197 Results

198 The mean contact angle of the control was found to be $86.06^{\circ}$. This was found to be far 199 greater in comparison to the acid treated samples. The mean contact angles of 30 minutes and 60 200 minutes $\mathrm{HNO}_{3}$ treated samples are $72.03^{\circ}$ and $69.73^{\circ}$, respectively, were significantly lower with 201 respect to untreated surface as shown in (Table 1). 
treated samples as shown in Fig. 2. No changes were observed in the functional groups of the untreated mPE, 30 minutes and 60 minutes $\mathrm{HNO}_{3}$ treated $\mathrm{mPE}$ however there is a slight decrease

205 in the intensity of transmittance is observed. There were alike peaks observed at wavelengths

$2062850 \mathrm{~cm}^{-1}$ and $2930 \mathrm{~cm}^{-1}$ belonging to the alkane group (C-H stretch). The peaks were also

207 found at $3313 \mathrm{~cm}-1(\mathrm{O}-\mathrm{H}$ stretching) corresponding to hydroxyl group, $1647 \mathrm{~cm}-1(\mathrm{C}=\mathrm{C}$

208 bending), $1470 \mathrm{~cm}-1(\mathrm{C}-\mathrm{H}$ bending) and at $725 \mathrm{~cm}-1$ (C-H rocking), belonging to the alkane

209 family but differ in their structures. A peak was also observed at $1020 \mathrm{~cm}^{-1}$ which belongs to the 210 C-O stretching.

211 The morphological analysis of the samples was done using the 3D Hirox Microscopy and

212 SEM where as the nanotopographic analysis of the sample was performed with the help of AFM.

213 The images obtained are shown in Fig. 3(A)- 3(F). Fig. 3(A) represents the 3D image of the 214 control and Fig. 3(B) shows its profiling image. Likewise, the Fig. 3(C) and Fig. 3(D) depict the

$2153 \mathrm{D}$ image and its profiling image of the thirty minutes $\mathrm{HNO}_{3}$ treated sample, respectively. 216 Similarly, Fig. 3(E) and Fig. 3(F) elucidates the 3D image and its profiling image of one hour

$217 \mathrm{HNO}_{3}$ treated mPE sample. The graph plotted with the values obtained from the 3D-Hirox digital

218 microscope is represented in Fig. 4. Here, each point in the profile line is measured and 219 computed. These points represent the height of the pits in mPE surface. Thus, in Fig. 4, the height 220 of the pits or pores is plotted against the area of the profile line. From this graph, it is palpable 221 that there is less number of pores of pits in case of the control mPE. It is found that the number of 222 pores, increased in the 30 minutes and found to be highest in 1 hour acid treated mPE sample.

223 The 1 hour $\mathrm{HNO}_{3}$ treated sample has the maximum number of pores with greater depth of

224 fissures and holes which was ascertained using the 3D profiling. Fig. 4 shows the depth of the 225 pores formed due to the etching effect of the $\mathrm{HNO}_{3}$ and it is evident that the control has the least 226 pore depth, followed by 30 minutes $\mathrm{HNO}_{3}$ treated sample and finally the one hour $\mathrm{HNO}_{3}$ treated 
227 sample. Hence, the duration of acid treatment has an impact on the surface porosity by affecting

228 the pore diameter or area. From the Fig. 4 , it is visible that $42.5 \mu \mathrm{m}$ was the highest height of the

229 pore in the case of 60 minutes $\mathrm{HNO}_{3}$ treated sample whereas the highest pore for the 30 minutes

$230 \mathrm{HNO}_{3}$ treated $\mathrm{mPE}$ was $30 \mu \mathrm{m}$ and $17.5 \mu \mathrm{m}$ for untreated $\mathrm{mPE}$. This shows the numerical values,

231 data on relative changes for clearly differentiating the etching effect of $\mathrm{HNO}_{3}$ on $\mathrm{mPE}$.

232 SEM imaging is another surface characterization method of the samples at the micro level

233 (Zhao et al, 2011). Topography of the mPE was investigated as shown in Fig. 5(A-C). It was

234 observed that the surface of $\mathrm{mPE}$ sample has very less or negligible pits under a $1500 \mathrm{x}$

235 magnification. However, on observing the SEM image of 30 minutes treated sample, it was found

236 that the surface of the treated samples has been etched by the acid exposure. A few number of pit

237 formation was also observed. However, the size and the number of the pits seems to increase in

238 case of the 60 minutes acid treated sample.

239 The AFM images are represented in Fig. 6 (A-C). Fig. 6(A), Fig. 6(B) and Fig. 6(C) are

240 the AFM image of the untreated, 30 minutes and 60 minutes $\mathrm{HNO}_{3}$ treated mPE sample,

241 respectively. From the results obtained, it was found that the mean value of Ra of untreated $\mathrm{mPE}$

242 film, 30 minutes and 60 minutes $\mathrm{HNO}_{3}$ treated mPE surface are 2.069 nm, $4.233 \mathrm{~nm}$ and 5.127

$243 \mathrm{~nm}$, respectively. The nanotopographic analysis of the samples was performed using AFM. Fig.

244 6(A) illustrates the 3D surface topography of the sample mPE. Here, it is observed that the

245 surface of the sample is even with less hills and valley structures in the untreated mPE sample.

246 On the other hand, Fig. 6(B) which is the 30 minutes $\mathrm{HNO}_{3}$ treated sample has more nano-

247 roughness compared to the control but less roughness than the 60 minutes $\mathrm{HNO}_{3}$ treated sample.

248 This shows that 60 minutes $\mathrm{HNO}_{3}$ treated sample has most number of hill and valley structure on

249 the surface of the sample.

250 The average tensile testing result of $\mathrm{mPE}$ before and after nitric acid treatment is

251 represented in Fig. 7(A-C). From the tensile stress-strain curve it is palpable that the elastic 
252 modulus of 30 minutes $\mathrm{HNO}_{3}$ treated $\mathrm{mPE}$ is $33.01 \mathrm{MPa}$ (Fig. 7B) and 60 minutes $\mathrm{HNO}_{3}$ treated

$253 \mathrm{mPE}$ is $34.75 \mathrm{MPa}$ (Fig. 7C) which are slightly greater than the elastic modulus of untreated mPE

254 31.32MPa (Fig. 7A). The elastic modulus, maximum force, elongation at maximum force and

255 work up to maximum force is given in table 2.

256 Prothrombin time and activated partial thromboplastin time tests were done on the three

257 samples, namely, untreated and 30 minutes and 60 minutes $\mathrm{HNO}_{3}$ treated. Their results of PT and

258 APTT were summarized in Fig. 8(A) and Fig. 8(B), respectively. Both PT and APTT

259 demonstrated an increase in their value for acid treated samples compared to the control. Mean

260 PT of untreated sample was observed to be $19.23 \mathrm{~s}$, whereas 30 and $60 \mathrm{~min} \mathrm{HNO}_{3}$ exposed

261 samples shown $19.86 \mathrm{~s}$ and $21.4 \mathrm{~s}$, respectively. Likewise, mean APTT was found to be $105.66 \mathrm{~s}$,

$262113 \mathrm{~s}$ and $136.33 \mathrm{~s}$ for untreated, 30 minutes and 60 minutes acid treated $\mathrm{mPE}$, respectively.

263 Statistical analysis of the untreated sample with the treated ones using one-way ANOVA

264 insinuates significant differences $(P<0.05)$ between them for both PT and APTT times after 60

265 minutes exposure.

266 Besides that, hemolysis is an important screening test, which provides quantification of

267 small levels of plasma hemoglobin that may not be assessed under in vivo conditions (Schopka et

268 al, 2010). The hemolysis test was conducted on treating samples and untreated sample for

269 investigating the effect of polymer surface on red blood cells (RBC). Mean absorbance seemed to

270 decrease in the case of treated samples $\left(0.02\right.$ and 0.007 for $30 \mathrm{~min}$ and $60 \mathrm{~min} \mathrm{HNO}_{3}$-treated

271 samples) compared with the untreated (0.05) $\mathrm{mPE}$, indicating lesser damage incurred and

272 interaction between the treated samples and RBC Fig. 8(C). This is because the absorbance is

273 directly proportional to the hemolytic index (HI) of the RBC. Statistical analysis of the untreated

274 as well as acid treated samples (absorbance at 542nm) using one-way ANOVA ascertained

275 significant differences $(P<0.05)$ between them after 30 minutes and 60 minutes treatment. From

276 the results obtained, it is obvious that the 60 minutes $\mathrm{HNO}_{3}$ treated $\mathrm{mPE}$ is the least hemolytic 
277 compared to other samples. Moreover, it was also found that an absorbance value of 60 minutes

$278 \mathrm{HNO}_{3}$ treated $\mathrm{mPE}$ to be in similar trend compared to the one hour $\mathrm{HCl}$ treated mPE (Jaganathan 279 et al, 2014).

280 Besides HI, the adhesion of platelets on a blood contacting device's surface could result in 281 coagulation and thrombus formation. Hence, the platelet adhesion test has to be performed to 282 analyze the blood compatibility of blood contacting device (Wenzhong et al, 2008). The number 283 of platelets adhered to a surface of treated polymers was found to be reduced to a great extent 284 compared to the number of platelets which was found in the untreated sample as shown in Fig. 285 9A. A maximum of 22 platelets was observed on the surface of the untreated samples (Fig. 9B), 286 meanwhile the number of platelets decreased to a maximum of 18 platelets (Fig. 9C) and 15 287 platelets (Fig. 9D) on 30 minutes and 60 minutes $\mathrm{HNO}_{3}$ treated samples, respectively. Statistical 288 analysis of the untreated sample with the treated one (number of platelets adhered) with one-way 289 ANOVA shown significant differences $(P<0.05)$ between them after 30 minutes and 60 minutes 290 treatment.

\section{Discussion}

Blood clotting occurs when blood comes in contact with a foreign surface such as 293 implants following platelet activation. This can be catastrophic in clinical settings, especially in 294 case of various biomedical applications like grafts, catheters, hemodialysis, bypass/extracorporeal 295 membrane oxygenation, and ventricular assist devices (Qi, Maitz \& Huang, 2013). In order to 296 circumvent this issue, the hemocompatibility of the blood contacting devices has to be improved 297 and $\mathrm{HNO}_{3}$ surface treated mPE holds a great potential. For ascertaining the topographical 298 modification caused by $\mathrm{HNO}_{3}$ on the mPE sample, characterization tests was performed using 3D

299 Hirox, SEM, AFM, contact angle and FTIR. On the other hand, the blood compatibility of the 300 sample was studied by conducting different blood coagulations assays like hemolysis assay, PT, 301 APTT, and platelet adhesion. 
303 mPE polymer. It is a well known fact that the surface energy is a vital parameter determining

304 polymer's adhesion, material wettability and even biocompatibility (Kwok, Wang \& Chu PK,

305 2005). Thus, the assessment of contact angles is contemplated as one of the most convenient

306 method for the determination of surface free energy of solid samples. This technique depends on

307 the interactions between the solid sample of interest as well as liquids with well determined

308 surface tensions. Our result is in good agreement with our previous published results of $\mathrm{HCl}$

309 exposed mPE (Jaganathan et al, 2014). Thus, the improved surface roughness is reflected in the

310 decrease in contact angle with $\mathrm{HNO}_{3}$ treatment time. Furthermore, in a recent work, Gomathi et

311 al., had performed surface modification of polypropylene by nitrogen containing plasma

312 improved the polymer's wettability by decreasing the water contact angle and resulted in

313 enhanced biocompatibility and blood compatibility further corroborates our results (Gomathi et

314 al, 2012). According to Wenzel model, the improvement in the surface roughness of $\mathrm{mPE}$

315 contributes to the reduction in the water contact angle of mPE (Chau et al, 2009). Thus, it

316 indirectly shows that the surface roughness of the mPE sample are improved by the $\mathrm{HNO}_{3}$

317 treatment, thereby decreasing the contact angle. Ultimately, the hydrophilicity and mPE

318 hemocompatibility is improved where it can serve as a putative blood contacting device (Zhao et

319 al, 2011). Similarly, the improved surface roughness is also palpable from the results of AFM,

320 SEM, Hirox 3D microscopy result. Hence, the decrease in the contact angle and increase in

321 surface roughness are in consensus from obtained result. This is analogous to the studies that

322 have ascertained that the increase in wettability is instigated by the increase in surface roughness

323 and associated decrease in the contact angle (Mirabedini et al. 2004; Mirzadeh \& Dadsetan 2003;

324 Rochotzki et al. 1994).

325 There is no alteration in the functional groups of the treated and untreated samples which

326 is done by Attenuated Total Reflectance Fourier Transform Infrared Spectroscopy (ATR-FTIR) 
327 studies. However, the variation in the intensity of the peaks depicts that there is some

328 morphological changes occurred. The surface changes induced in the metalocene polyethylene

329 (mPE) surface is instigated by the etching effect of nitric acid $\left(\mathrm{HNO}_{3}\right)$. The $\mathrm{HNO}_{3}$ exposure

330 produces pits and holes in the surface of $\mathrm{mPE}$. Owing to the formation of pits and pores in $\mathrm{mPE}$,

331 the surface roughness increases. The improved surface roughness of $\mathrm{mPE}$ is reflected in increased

332 intensity of absorbance in FTIR but the peaks remain almost the same, indicating no chemical

333 changes were seen in the surface of mPE. Bergström demonstrated that absorption heavily

334 depends upon the surface properties of the material (Bergström 2008). Since most real life

335 surfaces are not perfectly flat and possess certain degrees of texture and roughness to them, this

336 will influence their optical behaviour. Pits and valleys in a material may, for example, "trap"

337 some of the light and thereby increase the intensity of absorption. However, when the absorption

338 increases, the transmittance decreases.(Sorrell 2006) This explains the reason for the increased

339 absorption leading to decreased intensity of transmittance in this study, as the surface roughness

340 improves after $\mathrm{HNO}_{3}$ treatment. Hence, this elucidates that there is no change in the functional

341 groups in mPE surface, even after $\mathrm{HNO}_{3}$ treatment of $\mathrm{mPE}$ which is similar to our $\mathrm{HCl}$ exposed

342 mPE (Jaganathan et al, 2014). Thus, $\mathrm{HNO}_{3}$ treated mPE sample would have enhanced blood

343 compatibility without affecting the chemical structure of mPE since the surface roughness of the

$344 \mathrm{mPE}$ is increased by the $\mathrm{HNO}_{3}$ treatment rather than modifying the chemical structure of mPE.

345 The percentage of weight loss study was also performed, but the change in the weight of the

346 sample after $\mathrm{HNO}_{3}$ treatment was not significant which ascertains there is no strong oxidation

347 have occurred to increase the weight of the $\mathrm{HNO}_{3}$ treated mPE samples (result not shown). This is

348 in accordance with the FTIR result which didn't show appreciable changes in surface functional

349 groups. Thus, it can be elucidated as the improved surface roughness resulted in better

350 hydrophilicity and hemocompatibility of $\mathrm{HNO}_{3}$ treated $\mathrm{mPE}$ rather than the change induced in the

351 sample surface functional group by $\mathrm{HNO}_{3}$ treatment. 
353

354

355

356

357

358

359

360

361

362

363

364

365

366

367

368

369

370

371

372

373

374

375

376

and one hour acid treatment must have etched the mPE surface more than the 30 minutes treated

sample, thereby resulting in $\mathrm{mPE}$ with more pits and pores with higher depth compared to the

control. These observations can be compared to a later work of Vital et al., where the amplitude

of depressions formed in the surface of polymer increased after tetrahydrofuran (THF) and acetic

acid surface treatment whereas thickness of the polymer film remained unchanged (Vital et al,

2015). Hence, the etching effect of the acid has a favorable impact on the final surface wettability

of the polymer, thereby making it more hydrophilic similar to the other surface treatments like

plasma treatment to make it blood compatible for various blood contacting device applications

(Yue et al, 2014).

Similarly, a larger surface disorientation and improved surface roughness were noticed in 60 min treated sample using SEM images. The SEM images of a recent study show the morphology of isotactic polypropylene (IPP) surfaces of Argon plasma treatment, showing amorphous region is etched on the surface of IPP and the etching depth was found to be increasing with an increase in the time of plasma treated thereby improving its biocompatibility (Ma et al, 2011). Likewise, SEM images of the treated and untreated samples to clearly show that there are pits formed in the surface of the mPE polymer when it is treated with $\mathrm{HNO}_{3}$ and the pit size is also increased with the increase in the time of acid treatment. Since pits were formed, the morphological characteristic such as roughness was also observed to be increased in case of the $\mathrm{HNO}_{3}$ treated samples. It is obvious from the Fig. 5 that the number of pits formed in the sample is in the descending order of 60 minutes $\mathrm{HNO}_{3}, 30$ minutes $\mathrm{HNO}_{3}$ and then finally the control.

It was found that the $\mathrm{Ra}$ value of the 60 minutes $\mathrm{HNO}_{3}$ treated sample value is almost twice greater than the control and slightly higher than the 30 minutes $\mathrm{HNO}_{3}$ treated $\mathrm{mPE}$. This is because of more number of hills and valley nano-topographic structure in the mPE sample resulted due to the etching effect of the $\mathrm{HNO}_{3}$ on the mPE sample. This result is found to be 
377 similar to a latest study done by Cesca et al., where the AFM result obtained after poly-3-

378 caprolactone (PCL) etched using mixed gas SF6/Argon at $-5^{\circ} \mathrm{C}$ has an improved surface 379 roughness resulting in improved biocompatibility (Cesca et al, 2014). The roughness values 380 obtained using AFM also evidenced the surface structuring after subjecting the sample to surface 381 modification techniques to produce a rougher surface (Tverdokhlebov et al, 2014; Wanke et al, 382 2014). Similarly, there were other studies carried out show increase in surface roughness of 383 sample results in improved biocompatibility (Slepicka et al, 2013). Hence, AFM nano imaging 384 further bolsters the concept of nanotopographic surface modification caused by the acid etching 385 effect on mPE analyzed using Hirox microscopy and SEM. This formed nanotopographic surface 386 result in improved wettability and hydrophilicity ascertained by contact angle analysis, thereby 387 improving the blood compatibility of $\mathrm{mPE}$ which is the cornerstone for blood contacting devices.

388 Since nitric acid improves porosity and blood compatibility of mPE, the elastic modulus 389 of $\mathrm{mPE}$ was studied to make sure that the nitric acid treatment does not deteriorate the elastic 390 modulus of $\mathrm{mPE}$. There was no significant change was observed and minor improvement in the 391 elastic modulus of $\mathrm{HNO}_{3}$ treated $\mathrm{mPE}$ which may have resulted due to increase in the roughness 392 of the surface in $\mathrm{mPE}$. This result is in accordance with a recent study where the impact strength 393 of nitric acid treated polyoxymethylene improved compared to those untreated samples (Zhang et 394 al, 2014). The main advantage of the $\mathrm{HNO}_{3}$ over $\mathrm{HCl}$ is the improvement of hemocompatibility 395 without deteriorating the tensile strength of the mPE samples after treatment. The effect of $\mathrm{HCl}$ 396 on the tensile strength of $\mathrm{mPE}$ is not yet reported, but it was found that the $\mathrm{HCl}$ treatment 397 deteriorate the tensile strength of the sisal fiber (I. Oladele 2010). Similarly, in another work done 398 by Mingchao et al., the tensile strength of basalt fiber declines after the $\mathrm{HCl}$ exposure (Wang 399 Mingchao et al. 2008). However, the results of $\mathrm{HNO}_{3}$ exposure improved the tensile strength of 400 different polymers like polyacrylonitrile, carbon fibers, thermoplastic polyimide composite and 401 etc (Bahl 1984; Li 2009; Nie \& Li 2010). In our study $\mathrm{HNO}_{3}$ treatment did not reduce the tensile 
402 strength of mPE. Hence, the major advantage of $\mathrm{HNO}_{3}$ treatment over $\mathrm{HCl}$ treatment is the

403 deterioration of tensile strength of mPE can be prevented, in addition to the enhancement the

404 blood compatibility properties of mPE sample.

405 Coagulation system activation is triggered by implanting blood contacting device-protein

406 interaction. The activation of factor XII is the first step in this activation process. Reciprocal as

407 well as auto activation will in turn cause the amplification of activated factor XII, where this will

408 initiate the intrinsic coagulation pathway through activation of factor XI, and finally lead to the

409 production of fibrin. Similarly, the activation of platelets by artificial surfaces occurs due to the

410 contact of platelets with artificial surfaces, in terms of ligand expression (GP IIb/IIIa). Ultimately,

411 these activated platelets either adhere to the surface of blood contacting devices through proteins

412 like fibrinogen or aggregate (Schopka et al, 2010). In order to function as a viable blood

413 contacting devices, the implanted blood contacting device should not elicit any unwanted

414 reactions leading to blood clot. In order to investigate that, the blood coagulation assays were

415 carried out in the mPE treated with $\mathrm{HNO}_{3}$. There was a notable increase observed in the PT and

416 APTT of the $\mathrm{HNO}_{3}$ treated mPE sample compared to the control. Changes in surface morphology

417 of $\mathrm{mPE}$ by acid treatment helped in improving the blood compatibility of the polymers

418 (Pandiyaraj et al, 2008). Thus, as discussed earlier, the increased PT and APTT is may be

419 attributed by improved surface roughness by the formation of nanotopographic surface by $\mathrm{HNO}_{3}$ 420 on $\mathrm{mPE}$.

421 The improved surface roughness induces physicochemical changes which results in a 422 favorable impact on the hemocompatible property of mPE thereby making it more resistant to 423 RBCs damage. The lysis of RBCs generally occur due to the increase in osmotic pressure 424 triggered by the poor material surface which normally results in the rupture and release of the 425 cellular contents including hemoglobin (Zhang et al. 2015). Hemolysis percentage is the 
426 representative of RBCs damage. Hence, the improved surface roughness of $\mathrm{HNO}_{3}$ treated mPE

427 decreases the RBCs damage when they come in contact with them. According to ASTMF756-

$42800(2000)$ standard, both 30 and 60 min $\mathrm{HNO}_{3}$ treated samples are deduced to be non-hemolytic

429 materials since the percentage of damage falls below 2 (M. Fazley Elahi 2014). This result is in

430 agreement to one of the research elucidating that the surface roughness plays an important role in

431 controlling the thrombogenicity and it was demonstrated that catheters with increased roughness

432 were found to be less thrombogenic than smooth surfaced catheters (Bailly et al. 1999). This

433 means that the surface modification of $\mathrm{mPE}$ with $\mathrm{HNO}_{3}$ does not induce any damage in

434 erythrocytes' membranes that could lead to their lysis. Albeit some literatures indicate that it is

435 not possible to define a universal level of acceptable or unacceptable hemolysis values, a blood-

436 compatible material must inhibit hemolysis (Wenzhong et al, 2008). In this study, this parameter

437 is of extreme importance as the proposed $\mathrm{MPE}$ material will be in contact with blood for a

438 prolonged period in the blood circulation system.

The increased surface roughness of $\mathrm{HNO}_{3}$ treated mPE produces a better resistance to 440 platelets by minimizing the platelet adhesion. The extent of platelet adhesion as well as its 441 activation is a deciding factor of thrombogenecity of a material, as blood compatible substrates 442 neither attracts nor activates the platelets present in the blood stream. In general the hydrophilic 443 surface is observed to be more efficient in preventing the platelet adhesion. This is because; it has 444 the ability to exert steric repulsion to avoid unspecific protein deposition (Gomathi et al. 2010). 445 Moreover, the hydrophilic surface is also found to encourage the adsorption of anti-platelet 446 adhesion proteins like albumin, high molecular-weight kininogen, etc., which further bolsters it's 447 shielding capacity against platelet deposition and activation. These observations were evidently 448 replicated in the $\mathrm{HNO}_{3}$ treated mPE surfaces (Gomathi et al. 2010; Lee \& Lee 1998). The 449 obtained results are in consensus with other studies conducted on hydrophilic surface dictating 450 that improved surface roughness led to decreased platelet adhesion (Zingg et al. 1981; Zingg et 
451 al. 1982). Similarly, Zhao et al., demonstrated that when the NiTi alloy surface roughness was

452 increased, platelet activation, adhesion, as well as hemolysis were appreciably reduced (Zhao et

453 al. 2011). The reduced platelet adhesion in the $\mathrm{HNO}_{3}$ treated sample dictates the improved

454 hemocompatibility of surface modified mPE (Gomathi et al, 2012; Habibzadeh et al, 2014).

455 Thus, the possible mechanism from the obtained result of this study is the surface 456 roughness of mPE improves by the $\mathrm{HNO}_{3}$ treatment. When surface roughness of mPE increases,

457 it results in decrease in contact angle and increases the hydrophilicity of mPE. Hence, the 458 improved surface roughness minimizes the RBCs damage by reduction of osmotic pressure 459 triggered by the poor material surface and leads to decreased platelet adhesion by exerting steric 460 repulsion to avoid unspecific protein deposition. This is the possible mechanism by which the 461 blood compatibility of $\mathrm{HNO}_{3}$ treated $\mathrm{mPE}$ improves when it is compared against the control as 462 represented in Fig.10. Hence, this modified mPE with more surface roughness, altered 463 wettability, and better blood compatibility may be the vital characteristics that can be utilized for 464 construction of long-term blood contacting devices like catheters, transvenous pacing leads, 465 stents, grafts and etc.

\section{Conclusions}

467 The surface modification induced by $\mathrm{HNO}_{3}$ on $\mathrm{mPE}$ and its effect on $\mathrm{mPE}$ blood 468 compatibility was assessed. Contact angle analysis depicts a decrease in the contact angle 469 elucidating increase in the wettability of the $\mathrm{HNO}_{3}$ treated samples. There were no prominent 470 qualitative changes in the functional groups were observed by FTIR studies. The 3D Hirox 471 microscopy imaging also confirms the improved surface roughness by formation of more pits and 472 bumps in the acid treated sample than the control. SEM images of treated samples further 473 substantiate that acid treated sample surface possess more pits and pores compared to the control. 474 AFM topographical analysis shows an improved surface roughness in the 30 minutes and 60 475 minutes acid treated sample compared to the control due to the etching effect of the acid. Blood 
476 coagulation assays like PT and APTT ascertains a notable delay in the clotting mechanism on the

477 surface of acid treated samples. The result of hemolysis assay shows a minimum damage to red

478 blood cells (RBC). Platelet adhesion assay elucidates that the number of platelets adhered to the

479 surface of acid treated polymer was appreciably less in comparison to the untreated surface. The

$480 \mathrm{HNO}_{3}$ treatment of the mPE induces a surface modification in mPE and improves its porosity

481 without much effect on its tensile strength. Hence, $\mathrm{HNO}_{3}$ treated $\mathrm{mPE}$ sample can be exploited

482 for various blood contacting biomaterial applications due to its improved blood compatibility.

483 Acknowledgments

484 The authors would like to thank MSI Technologies (M) Sdn. Bhd and Progene for 485 providing us KH-8700 3D Hirox Microscope for imaging our samples. The authors would also 486 like to thank Zwick International for helping us in analysis of the tensile data.

488 References

489 Amarnath LP, Srinivas A, Ramamurthi A. 2006. In vitro hemocompatibility testing of uv490 modified hyaluronan hydrogels. Biomaterials $\quad 27: 1416-1424 \quad$ DOI $491 \quad$ 10.1016/j.biomaterials.2005.08.008.

492 Bahl OP, Mathur RB and Dhami TL. 1984. Effects of surface treatment on the mechanical 493 properties of carbon fibers. Polymer Engineering \& Science, 24: 455-459. DOI 494 10.1002/pen.760240702.

495 Bailly AL, Lautier A, Laurent A, Guiffant G, Dufaux J, Houdart E, Labarre D, and 496 Merland JJ. 1999. Thrombosis of angiographic catheters in humans: experimental study. Int $J$ 497 Artif Organs 22:690-700.

498 Bergström D. 2008. The absorption of laser light by rough metal surfaces Doctoral. Luleå 499 University of Technology.

500 Cesca F, Limongi T, Accardo A, Rocchi A, Orlando M, Shalabaeva V, Fabrizio D, Benfenati. 501 2014. Fabrication of biocompatible free-standing nanopatterned films for primary neuronal 502 cultures. RSC Advances 4:45696-45702 DOI 10.1039/C4RA08361J.

503 Chau TT, Bruckard WJ, Koh PTL, Nguyen AV. 2009. A review of factors that affect contact 504 angle and implications for flotation practice. Advances in Colloid and Interface Science 150: 106505115 DOI 10.1016/j.cis.2009.07.003. 
506 Dong C, Eldawud R, Perhinschi G, Rojanasakul Y, Dinu CZ. 2013. Effects of acid treatment 507 on structure, properties and biocompatibility of carbon nanotubes. Applied Surface Science 264:

508 261-268 DOI 10.1016/j.apsusc.2012.09.180.

509 Fazley M. 2014. Hemocompatibility of surface modified silk fibroin materials: a review. RevAdv 510 Mater Sci 38:148-159.

511

512 Ferreira P, Coelho JFJ, Gil MH. 2008. Development of a new photocrosslinkable

513 biodegradable bioadhesive. International Journal of Pharmaceutics 352:172-181 DOI

514 10.1016/j.ijpharm.2007.10.026

515 Formanek G, Frech RS. 1970. Arterial thrombus formation during clinical percutaneous 516 catheterization. Circulation 41:833-839 DOI 10.1161/01.CIR.41.5.833.

517 Gomathi N, Eswaraiah C, and Neogi S. 2009. Surface modification of polycarbonate by radio518 frequency plasma and optimization of the process variables with response surface methodology. 519 Journal of Applied Polymer Science 114:1557-1566 DOI 10.1002/app.30691.

520 Gomathi N, Mishra D, Maiti TK, and Neogi S. 2010. Helium Plasma Treatment to Improve 521 Biocompatibility and Blood Compatibility of Polycarbonate. Journal of Adhesion Science and 522 Technology 24:2237-2255 DOI 10.1163/016942410X511088.

523 Gomathi N, Rajasekar R, Babu RR, Mishrag D, Neogib S. 2012. Development of bio/blood 524 compatible polypropylene through low pressure nitrogen plasma surface modification. Materials 525 Science and Engineering: C 32:1767-1778 DOI 10.1016/j.msec.2012.04.034.

526 Habibzadeh S, Li L, Shum-Tim D, Davis EC, Omanovic S. 2014. Electrochemical polishing as 527 a 3161 stainless steel surface treatment method: Towards the improvement of biocompatibility. 528 Corrosion Science 87:89-100 DOI 10.1016/j.corsci.2014.06.010.

529 Harrick NJ, and Beckmann KH. 1974. Internal Reflection Spectroscopy. In: Kane P, and 530 Larrabee G, eds. Characterization of Solid Surfaces: Springer US, 215-245 DOI 10.1007/978-1531 4613-4490-2_11.

532 Ivanira Antunes Perrenoud ECR, Rogério Pinto Mota, Steven Frederick Durrant, and 533 Nilson Cristino da Cruz. 2010. Evaluation of Blood Compatibility of Plasma Deposited 534 Heparin-like Films and SF6 Plasma Treated Surfaces. Materials Research 13:95-98 DOI 535 10.1590/S1516-14392010000100019.

536 Jaganathan SK, Mohandas H, Sivakumar G, Kasi P, Sudheer T, Veetil S. A, Murugesan S, 537 Supriyanto E. 2014a. Enhanced blood compatibility of metallocene polyethylene subjected to 538 hydrochloric acid treatment for cardiovascular implants. BioMed Research International 1-7 DOI $53910.1155 / 2014 / 459465$. 
540 Jaganathan SK, Supriyanto E, Murugesan S, Balaji A, Asokan MK. 2014b. Biomaterials in

541 Cardiovascular Research: Applications and Clinical Implications. BioMed Research International

542 1-11 DOI 10.1155/2014/459465.

543 John AA, Subramanian SP, Vellayappan MV, Balaji A, Jaganathan SK, Mohandas H, 544 Paramalinggam T, Supriyanto E, Yusof M. 2015. Review: physico-chemical modification as a 545 versatile strategy for the biocompatibility enhancement of biomaterials. RSC Advances 5: 3923254639244 DOI 10.1039/C5RA03018H.

547

548 Kealy TJ, Pauson PL. 1951. A new type of organo-iron compound. Nature 168:1039-1040 DOI 549 10.1038/1681039b0.

550 Kwok SCH, Wang J, Chu PK. 2005. Surface energy, wettability, and blood compatibility 551 phosphorus doped diamond-like carbon films. Diamond and Related Materials 14:78-85 DOI 552 10.1016/j.diamond.2004.07.019.

553 Lee JH, and Lee HB. 1998. Platelet adhesion onto wettability gradient surfaces in the absence 554 and presence of plasma proteins. J Biomed Mater Res 41:304-311 DOI 10.1002/(SICI)1097555 4636(199808)41:2<304::AID-JBM16>3.0.CO;2-K.

556 Li G, Zhang F, Liao Y, Yang P, and Huang N. 2010. Coimmobilization of heparin/fibronectin 557 mixture on titanium surfaces and their blood compatibility. Colloids Surf B Biointerfaces 81:255558262 DOI 10.1016/j.colsurfb.2010.07.016.

559 Li J. 2009. Effect of nitric acid surface treatment on tensile and tribological properties of 560 thermoplastic polyimide composite filled with carbon fibre. Plastics Rubber and Composites 561 38:243-247 DOI http://dx.doi.org/10.1179/174328909X435357.

562 Ma G, Liu B, Li C, Huang D, Sheng J. 2012. Plasma modification of polypropylene surfaces 563 and its alloying with styrene in situ. Applied Surface Science 258:2424-2432 DOI 564 10.1016/j.apsusc.2011.10.065.

565 Mirabedini SM, Rahimi H, Hamedifar S, and Mohsen Mohseni S. 2004. Microwave 566 irradiation of polypropylene surface: a study on wettability and adhesion. International Journal 567 of Adhesion and Adhesives 24:163-170 DOI 10.1016/j.ijadhadh.2003.09.004.

568 Mirzadeh H, and Dadsetan M. 2003. Influence of laser surface modifying of polyethylene 569 terephthalate on fibroblast cell adhesion. Radiation Physics and Chemistry 67:381-385 DOI 570 10.1016/S0969-806X(03)00071-9.

571 Mohandas H, Sivakumar G, Kasi P, Jaganathan SK, Supriyanto E. 2013. Microwave572 assisted surface modification of metallocene polyethylene for improving blood compatibility.

573 BioMed Research International 21-7 DOI 10.1155/2013/253473.

574 Moreno-Castilla C, Ferro-Garcia MA, Joly JP, Bautista-Toledo I, Carrasco-Marin F, 575 Rivera-Utrilla J. 1995. Activated carbon surface modifications by nitric acid, hydrogen 
576 peroxide, and ammonium peroxydisulfate treatments. Langmuir: the ACS journal of surfaces and

577 colloids 4386-4392 DOI 10.1021/la00011a035

578 Nie WZ, and $\mathbf{L i}$ J. 2010. Effects of plasma and nitric acid treatment of carbon fibers on the 579 mechanical properties of thermoplastic polymer composites. Mechanics of Composite Materials 580 46:251-256 DOI 10.1007/s11029-010-9143-0.

581 Oladele I. 2010. Investigating the Effect of Chemical Treatment on the Constituents and Tensile 582 Properties of Sisal Fibre. Journal of Minerals and Materials Characterization and Engineering 583 9:569-582 DOI 10.4236/jmmce.2010.96041.

584 Pelagade SM, Rane RS, Mukherjee S, Deshpande UP, Ganesan V, Shripathi T. 2012. 585 Investigation of surface free energy for ptfe polymer by bipolar argon plasma treatment. Journal 586 of Surface Engineered Materials and Advanced Technology 2:132-136 DOI 587 10.4236/jsemat.2012.22021

588 Pereira C, Busani T, Branco LC, Joosten I, Sandu IC. 2013. Nondestructive characterization 589 and enzyme cleaning of painted surfaces: Assessment from the macro to nano level. Microscopy 590 and Microanalysis 19:1632-1644 DOI 10.1017/S1431927613013196

591 Pandiyaraj KN, Selvarajan V, Rhee YH, Kim HW, Shah SI. 2009. Glow discharge plasma592 induced immobilization of heparin and insulin on polyethylene terephthalate film surfaces 593 enhances anti-thrombogenic properties. Materials Science and Engineering: C 29:796-805 DOI 594 10.1016/j.msec.2008.07.013.

595 Qi P, Maitz MF, Huang N. 2013. Surface modification of cardiovascular materials and implants.

596 Surface and Coatings Technology 233:80-90 DOI 10.1016/j.surfcoat.2013.02.008

597 Rochotzki R, Nitschke M, Arzt M, and Meichsner J. 1994. Plasma Modification of Polymer 598 Films Studied by Ellipsometry and Infrarot Spectroscopy. physica status solidi (a) 145:289-297 599 DOI 10.1002/pssa.2211450209.

600 Schopka S, Schmid T, Schmid C, Lehle K. 2010. Current strategies in cardiovascular 601 biomaterial functionalization. Materials 3:638-655 DOI 10.3390/ma3010638.

602 Slepicka P, Kasálková N, Slepcková N, Stránská E, Bacáková L, Švorcík V. 2013. Surface 603 characterization of plasma treated polymers for applications as biocompatible carriers. eXPRESS 604 Polymer Letters 7:535-545 DOI 10.3144/expresspolymlett.2013.50.

605 Sorrell TN. 2006. Organic Chemistry: University Science Books, Sausalito, California.

606 Thompson. 2013. M. Medtech Insight Reports.

607 Tverdokhlebov SI, Bolbasov EN, Shesterikov EV, Antonovab LV, Golovkinb AS, Matveeva 608 VG, Petlin DG, Anissimov YG. 2015. Modification of polylactic acid surface using rf plasma 609 discharge with sputter deposition of a hydroxyapatite target for increased biocompatibility. 610 Applied Surface Science 329:32-39 DOI 10.1016/j.apsusc.2014.12.127. 
611 Vascular Access 2006 Work Group. 2006. American Journal of Kidney Diseases 176-S247.

612 Vital A, Vayer M, Sinturel C, Tillocher T, Lefaucheux P, Dussart R. 2015. Polymer masks for 613 structured surface and plasma etching. Applied Surface Science 332:237-246 DOI 614 10.1016/j.apsusc.2015.01.040.

615 Vellayappan MV, Balaji A, Subramanian AP, John AA, Jaganathan SK, Murugesan S, 616 Supriyanto E, Mustafa Y. 2015a. Multifaceted prospects of nanocomposites for cardiovascular 617 grafts and stents. International Journal of Nanomedicine 10:2785-2803.

618 Vellayappan MV, Balaji A, Subramanian AP, John AA, Jaganathan SK, Murugesan S, 619 Hemanth S, Supriyanto E, Mustafa Y. 2015b. Tangible nanocomposites with diverse properties 620 for heart valve application. Science and Technology of Advanced Materials 16: 1-18 DOI 621 10.1088/1468-6996/16/3/033504.

622 Wang Mingchao, Zhang Zuoguang, Li Yubin, Li Min, and Sun Zhijie. 2008. Chemical 623 Durability and Mechanical Properties of Alkali-proof Basalt Fiber and its Reinforced Epoxy 624 Composites. Journal of Reinforced Plastics and Composites 27:393-407 DOI $62510.1177 / 0731684407084119$.

626 Wanke CH, Feijó JL, Barbosa LG, Campo LF, Oliveira RVB, Horowitz F. 2011. Tuning of 627 polypropylene wettability by plasma and polyhedral oligomeric silsesquioxane modifications. 628 Polymer 52:1797-1802 DOI 10.1016/j.polymer.2011.01.064.

629 Wenzhong S, Li, Liu Z, Yihong. 2008. Surface chemical functional groups modification of 630 porous carbon. Recent Patents on Chemical Engineering 1:27-40 DOI $631 \quad 10.2174 / 2211334710801010027$.

632 Xu Q, Yang Y, Yang J, Wang X, Wang Z, Wang Y. 2013. Plasma activation of porous 633 polytetrafluoroethylene membranes for superior hydrophilicity and separation performances via 634 atomic layer deposition of $\mathrm{tio}_{2}$. Journal of Membrane Science 443:62-68 DOI 635 10.1016/j.memsci.2013.04.061.

636 Yue M, Zhou B, Jiao K, Qiana X, Xua Z, Tenga K, Zhaoa L, Wang J, Jiao Y. 2015. 637 Switchable hydrophobic/hydrophilic surface of electrospun poly (l-lactide) membranes obtained 638 by cf4 microwave plasma treatment. Applied Surface Science 327:93-99 DOI 639 10.1016/j.apsusc.2014.11.149.

640 Zhang Q, Liao J-F, Shi X-H, Qiu Y-G, and Chen H-J. 2015. Surface biocompatible 641 construction of polyurethane by heparinization. Journal of Polymer Research 22:1-12 DOI 642 10.1007/s10965-015-0700-z.

643 Zhang Y, Zhu S, Liu Y, Yang Band Wang X. 2014. The mechanical and tribological properties 644 of nitric acid-treated carbon fiber-reinforced polyoxymethylene composites. Journal of Applied 645 Polymer Science 132:41812 DOI 10.1002/app.41812 
646 Zhao T, Li Y, Gao Y, Xiang Y, Chen H, Zhang T, 2011. Hemocompatibility investigation of the 647 niti alloy implanted with tantalum. Journal of Materials Science: Materials in Medicine 22: 23116482318 DOI 10.1007/s10856-011-4406-4.

649 Zingg W, Neumann AW, Strong AB, Hum OS, and Absolom DR. 1981. Platelet adhesion to 650 smooth and rough hydrophobic and hydrophilic surfaces under conditions of static exposure and 651 laminar flow. Biomaterials 2:156-158 DOI 10.1016/0142-9612(81)90042-9.

652 Zingg W, Neumann AW, Strong AB, Hum OS, and Absolom DR. 1982. Effect of surface 653 roughness on platelet adhesion under static and under flow conditions. Can J Surg 25:16-19.

654

655

656

657

658

659

660

661

662

663

664

665

666

667

668

669 


$$
\begin{array}{lll} 
& & \begin{array}{l}
\text { A. } 30 \text { minutes } \mathrm{HNO}_{3} \\
\text { treated mPE }
\end{array} \\
\text { Untreated } & \mathrm{HNO}_{3} \text { treatment on } & \begin{array}{l}
\text { B. } 60 \text { minutes } \mathrm{HNO}_{3} \\
\text { treated mPE }
\end{array}
\end{array}
$$

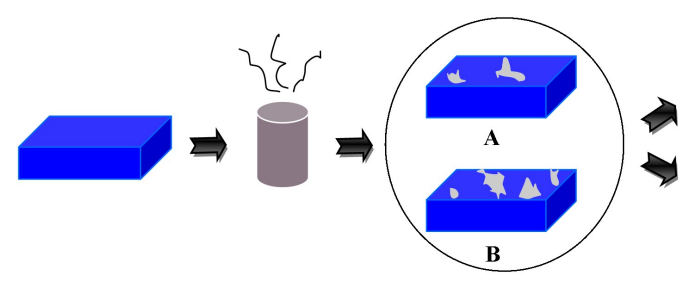

tests

\section{Blood coagulation} assays
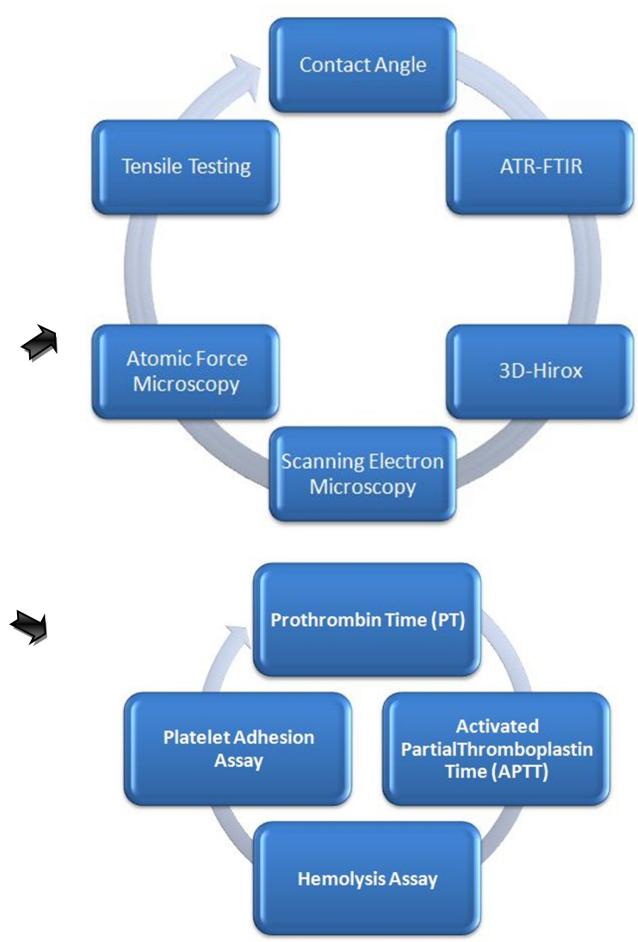

674 Figure 1 Schematic representation of series of characterization and blood compatibility 675 experiments done. 


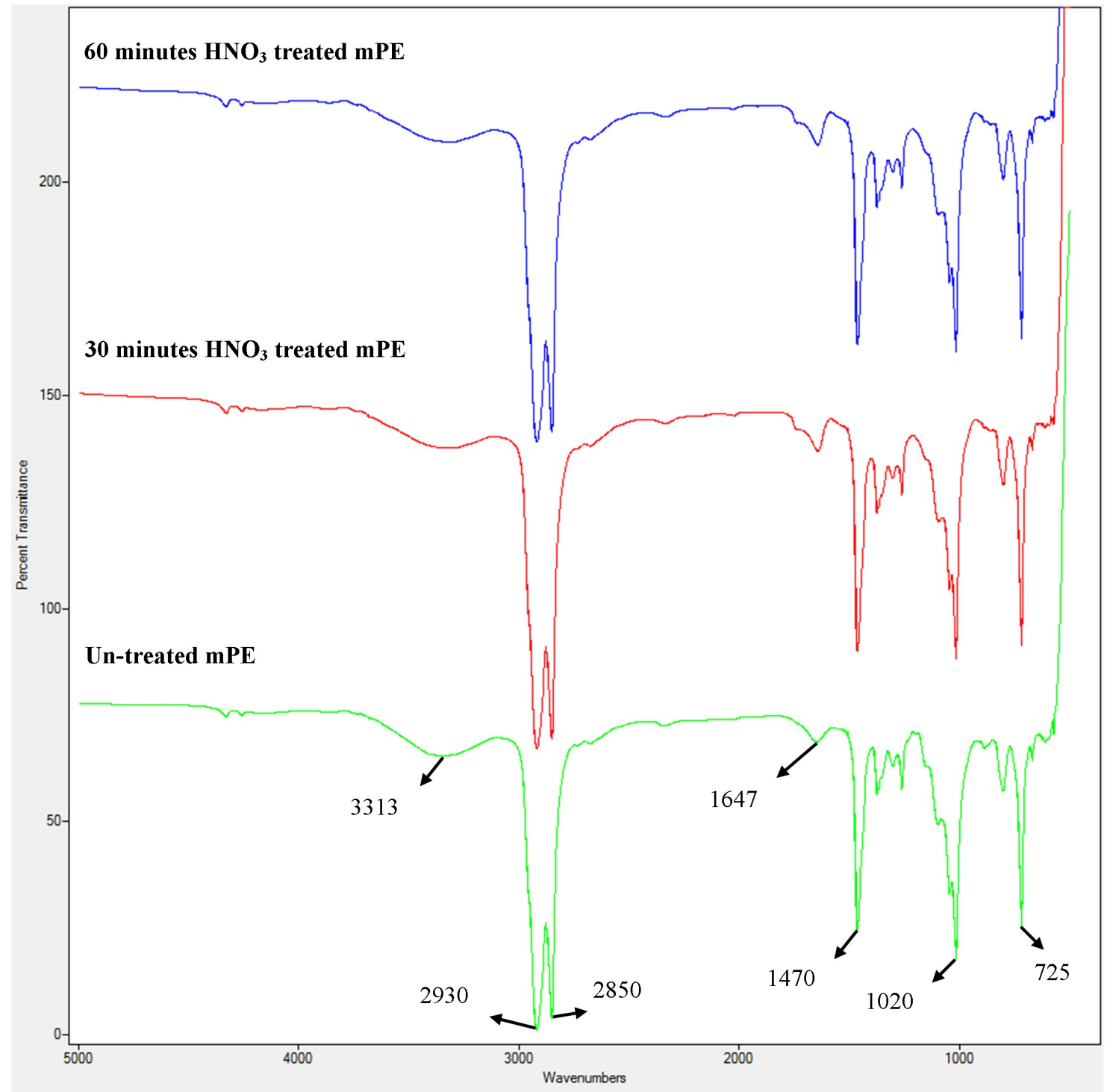

681

682

683

684

685

Figure 2 A representative FTIR spectra of untreated and $\mathrm{HNO}_{3}$ treated mPE. 


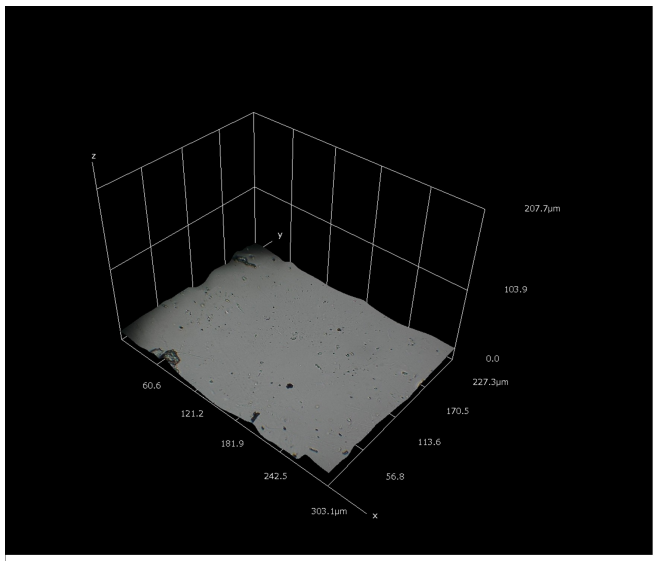

A

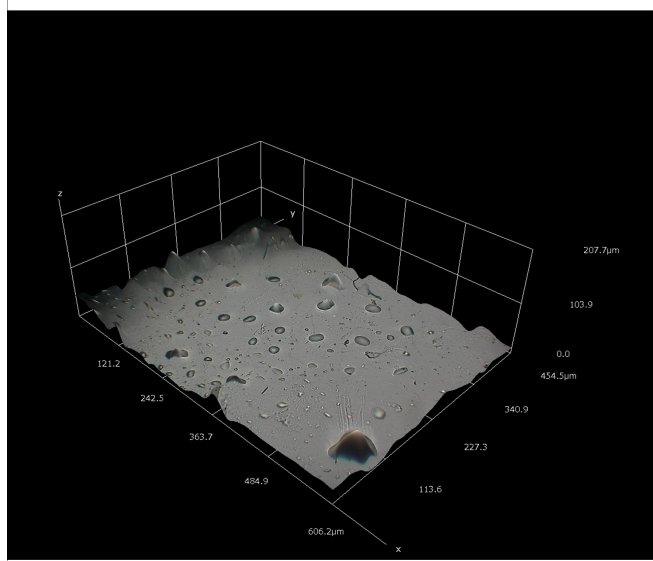

C

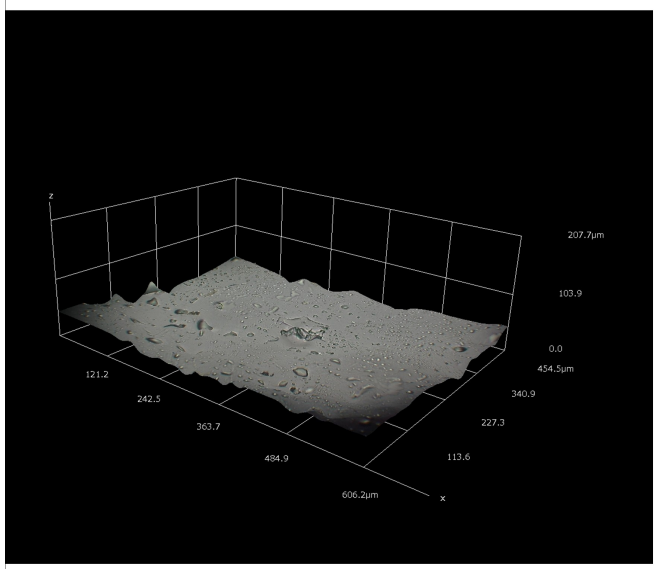

$\mathbf{E}$

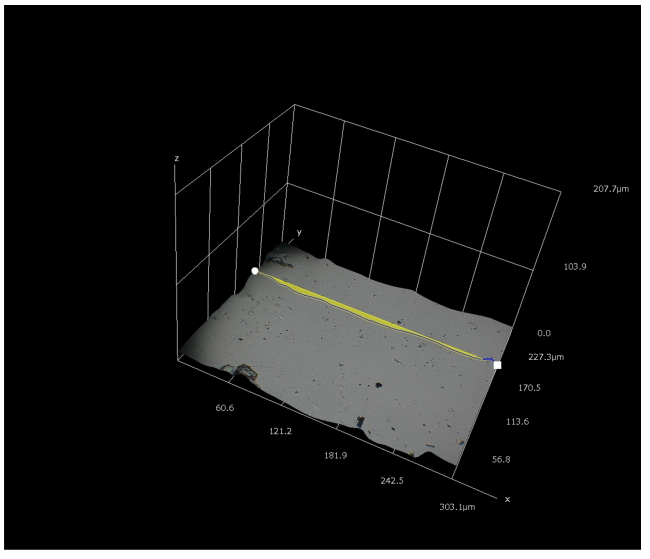

B

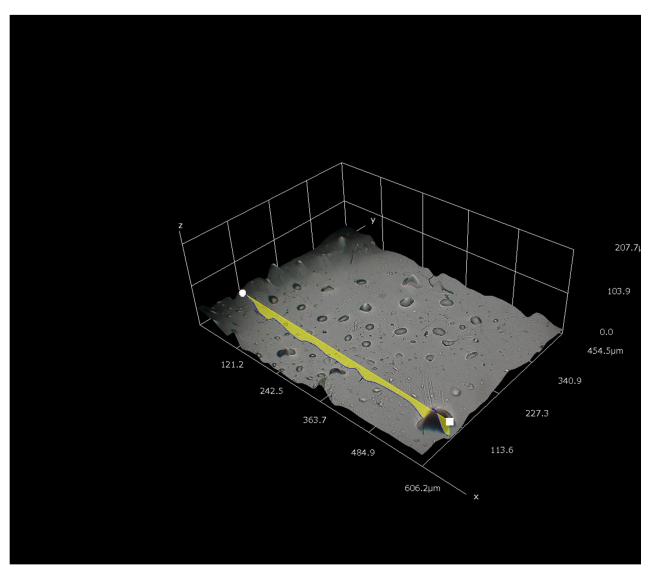

D

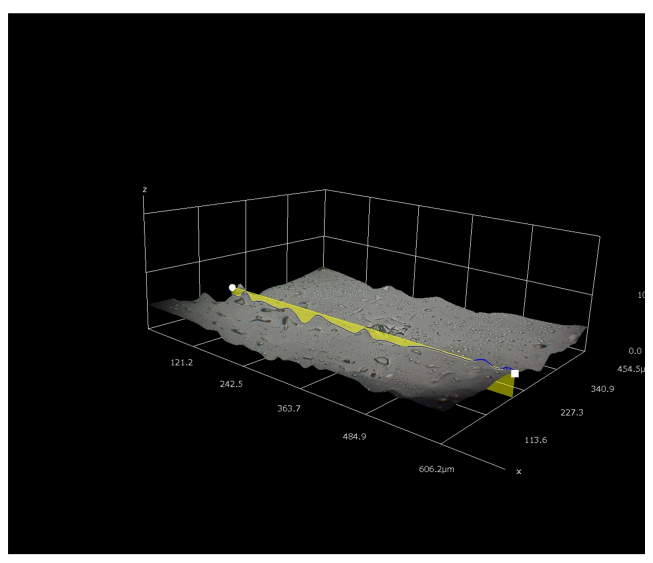

F

688 Figure 3 Different three-dimensional representations using 3D Hirox digital microscopy. (A) 689 Untreated mPE (B) Untreated mPE with profiling (C) 30 minutes $\mathrm{HNO}_{3}$ treated mPE (D) 30 690 minutes $\mathrm{HNO}_{3}$ treated mPE with profiling (E) 60 minutes $\mathrm{HNO}_{3}$ treated mPE (F) 60 minutes $691 \mathrm{HNO}_{3}$ treated $\mathrm{mPE}$ with profiling. 


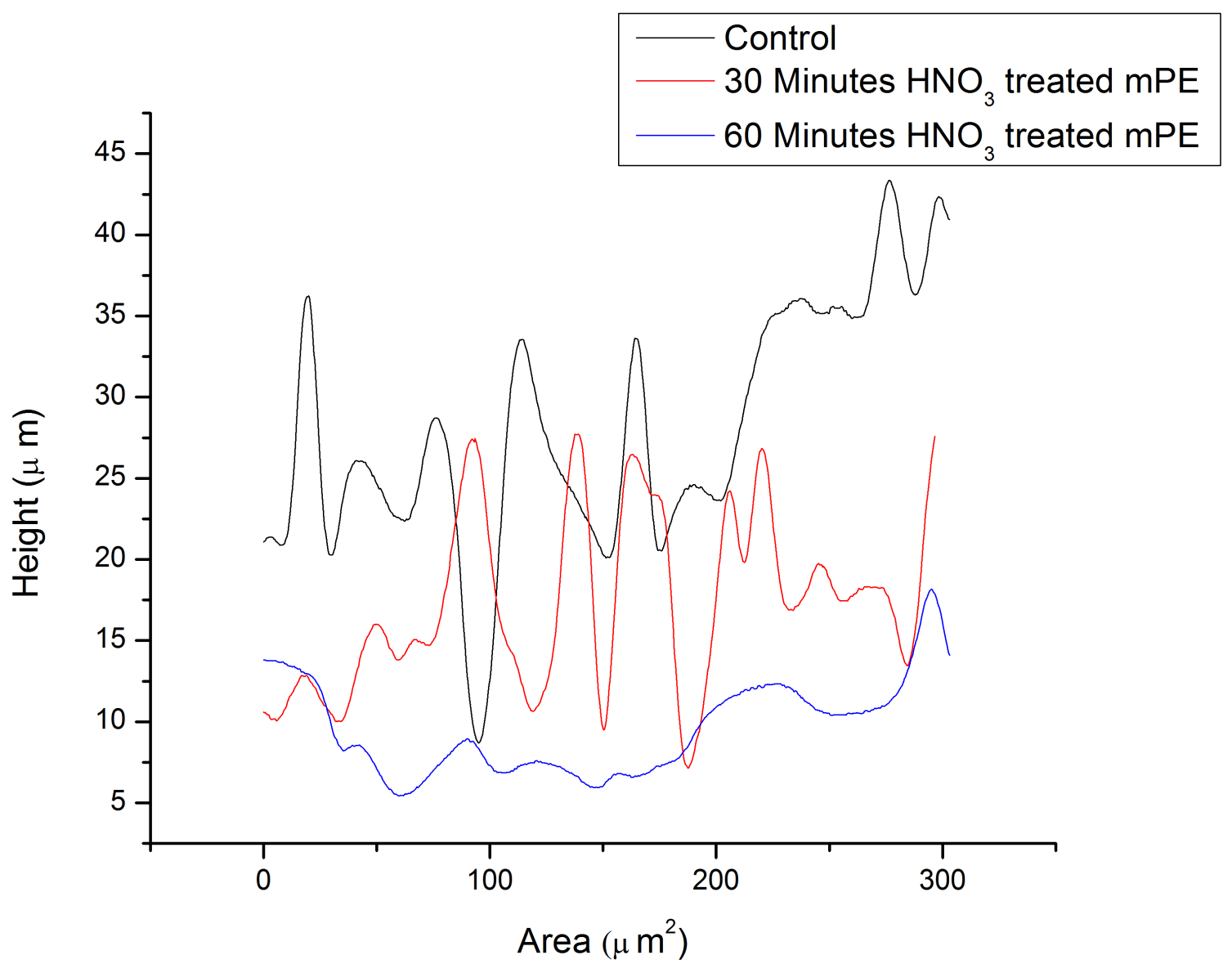

692

693

694

695

696

697

698

699 Figure 4 The representative height of the pores of different samples measured using 3D-profiling

700 of 3D Hirox digital microscopy.

701

702

703

704

705

706

707

708

709

710

711

712

713

714

715

716 
717

718

719

720

721

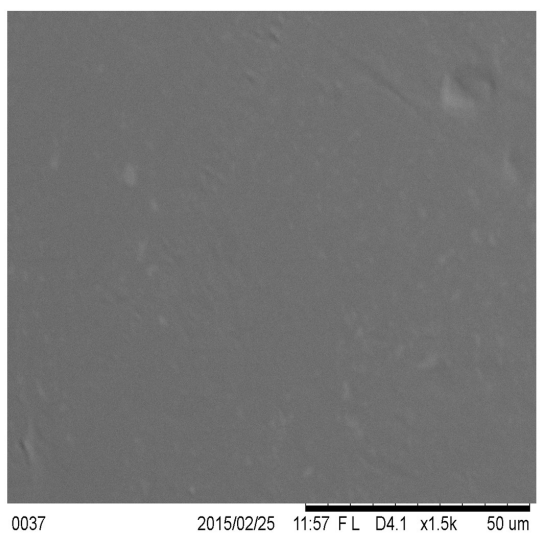

A

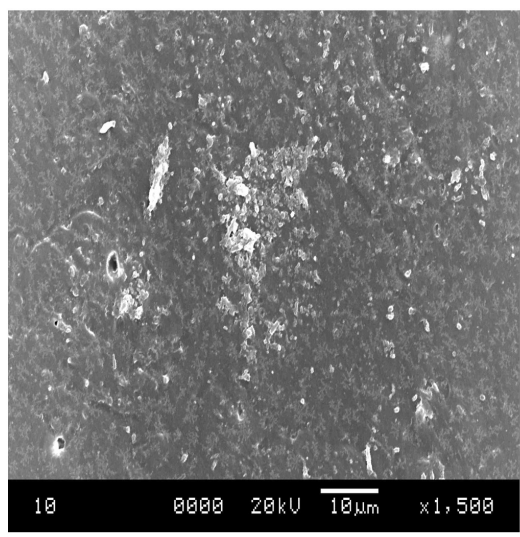

B

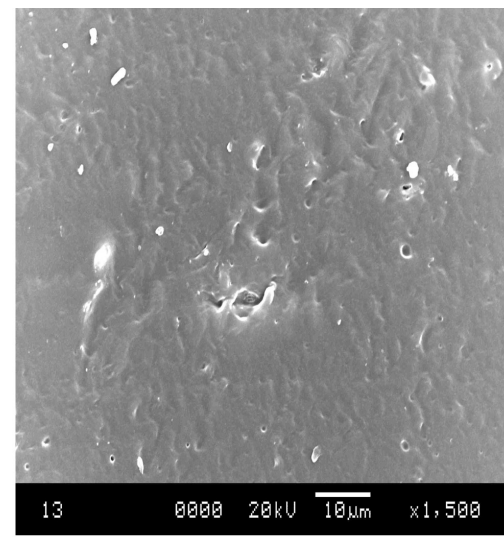

C
723

724

725

726

727

728

729

730

731

732

733

734

735

736

737

738

739

740

741

742

743

744

745

746

747

748

749

750 


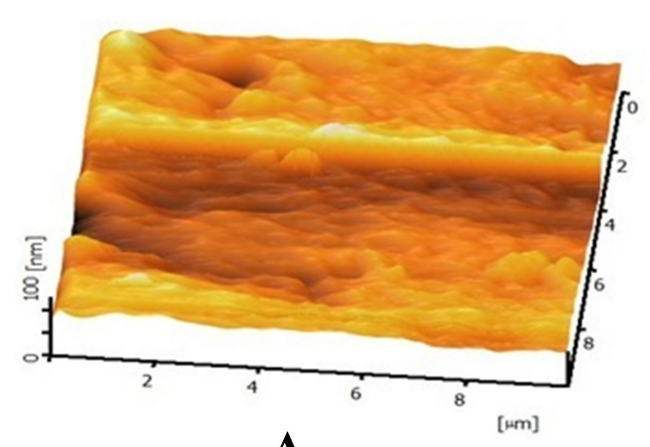

A

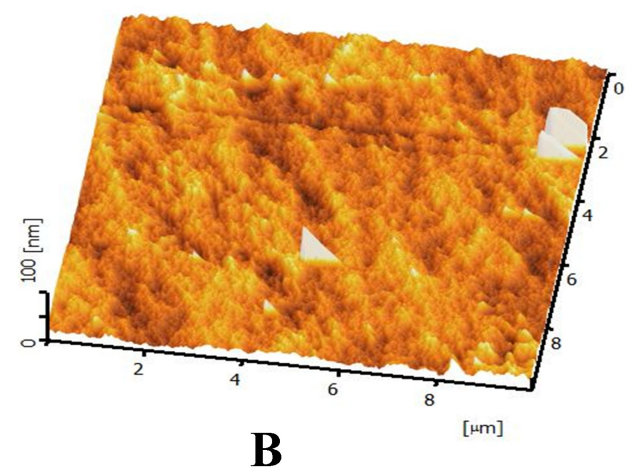

B

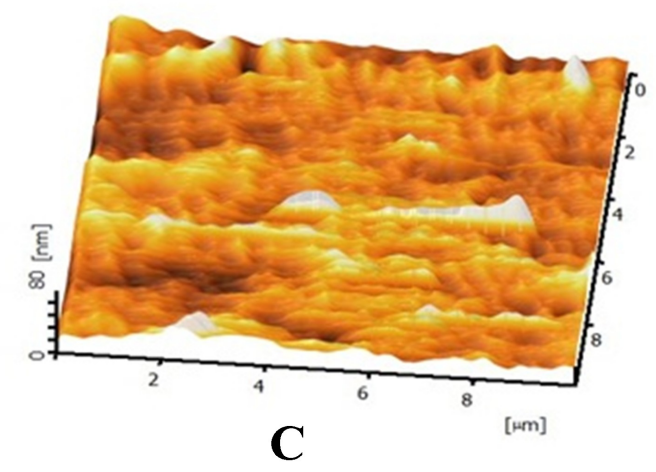

Figure 6 Representative AFM images of untreated and $\mathrm{HNO}_{3}$ treated mPE. (A) Untreated mPE (B) 30 minutes $\mathrm{HNO}_{3}$ treated mPE (C) 60 minutes $\mathrm{HNO}_{3}$ treated $\mathrm{mPE}$ 

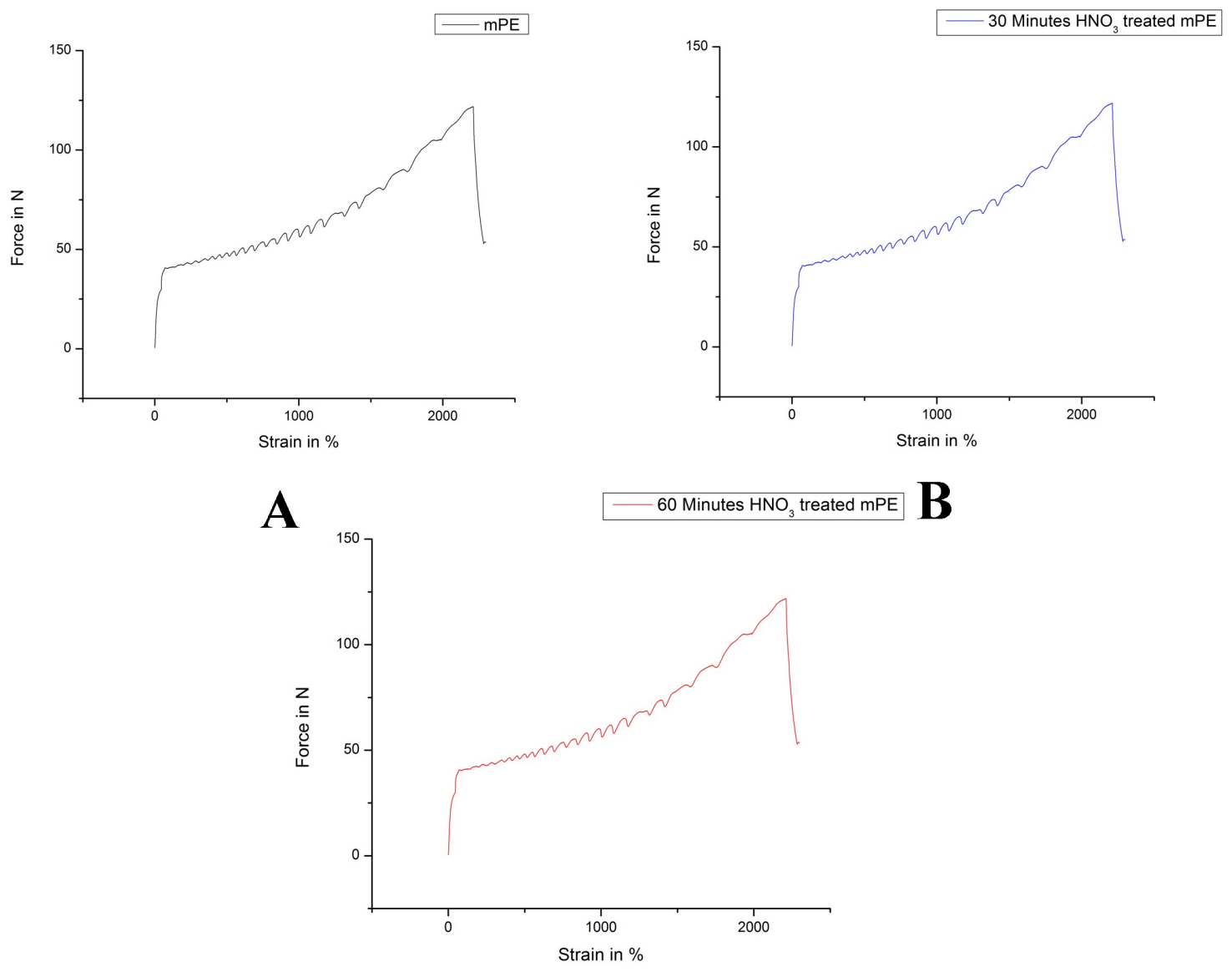

C

Figure 7 Representative tensile testing result of untreated and $\mathrm{HNO}_{3}$ treated mPE. (A) Untreated mPE (B) 30 minutes $\mathrm{HNO}_{3}$ treated mPE (C) 60 minutes $\mathrm{HNO}_{3}$ treated mPE. 


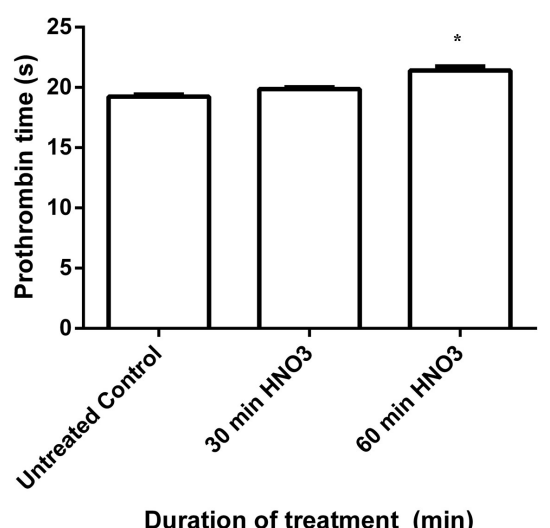

A

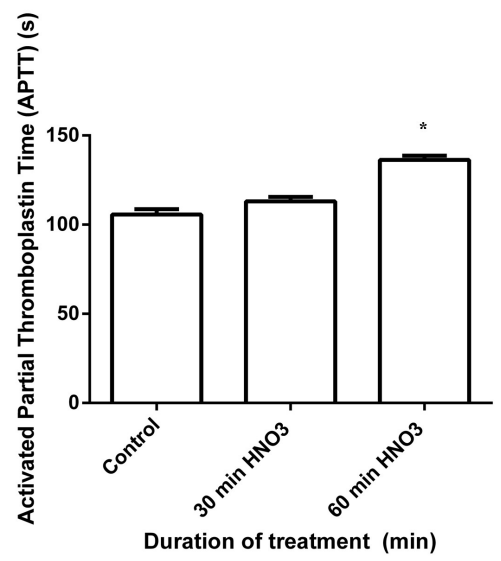

B

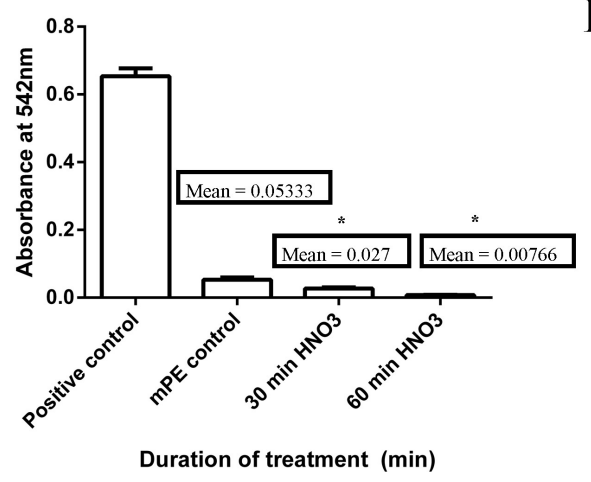

809 Figure 8 Comparison of prothrombin time (PT), activated partial thromboplastin time (APPT)

810 and absorbance of untreated and $\mathrm{HNO}_{3}$ treated mPE. (A) The PT of control, 30 minutes and 60

811 minutes $\mathrm{HNO}_{3}$ treated mPE $(n=3)(\mathrm{B})$ The APPT of control , 30 minutes and 60 minutes $\mathrm{HNO}_{3}$

812 treated mPE $(n=3)$ (C) The absorbance of control, 30 minutes and 60 minutes $\mathrm{HNO}_{3}$ treated

$813 \mathrm{mPE}(n=3)$. For all three panels, values shown are mean $\pm \mathrm{SD}$ and $*$ indicating differences in

814 the mean are significant $(P<0.05)$.

815

816 


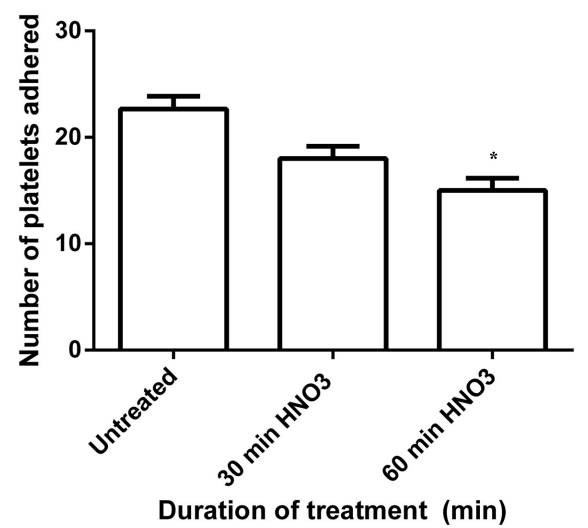

A
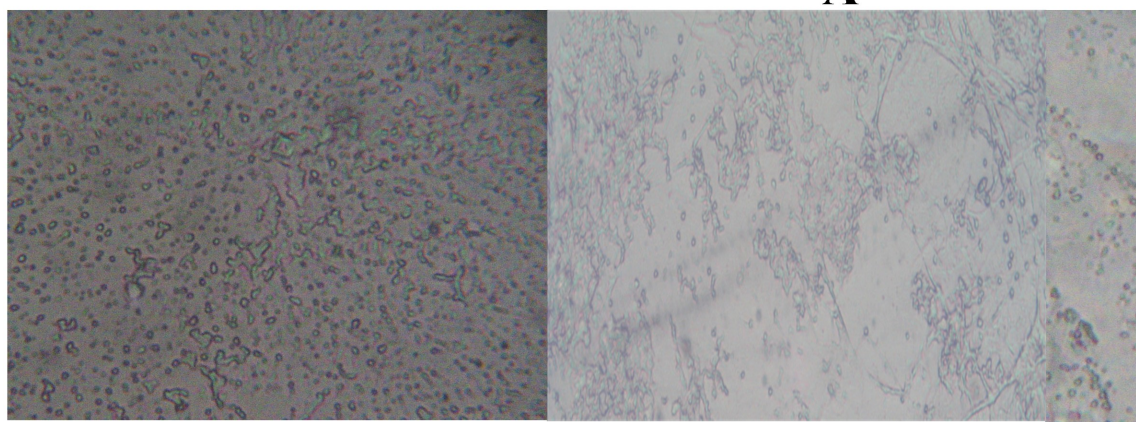

B

C

D

824 Figure 9 Platelet adhesion assay of untreated and $\mathrm{HNO}_{3}$ treated $\mathrm{mPE}$. (A) Comparison of the 825 number of platelets adhered untreated, 30 minutes and 60 minutes $\mathrm{HNO}_{3}$ treated mPE. Values are expressed as mean $\pm \mathrm{SD}$ and $*$ indicates difference in the means are significant with $P<0.05$ Number of platelets adhered on untreated mPE (C) Number of platelets adhered on 30 minutes 


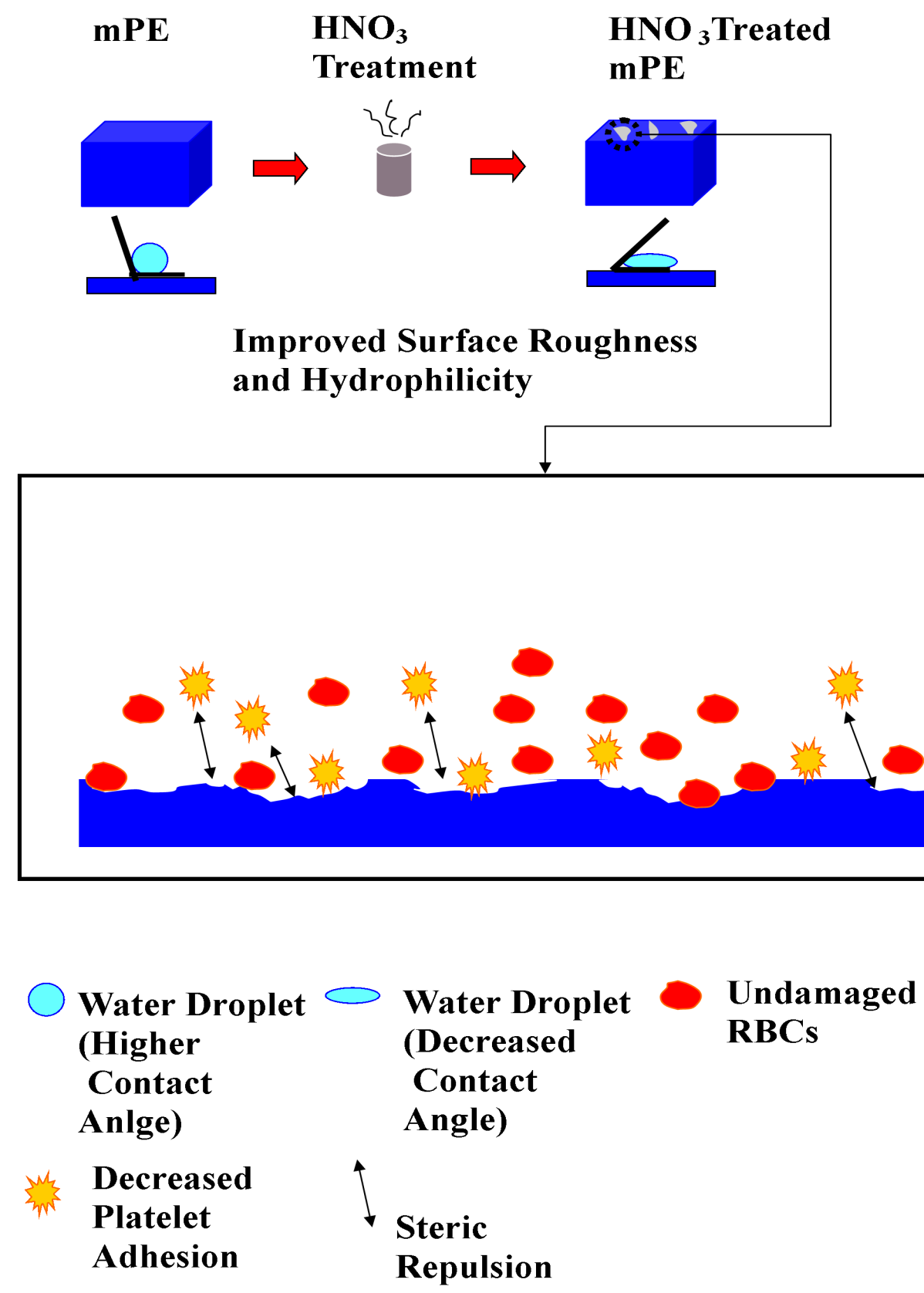

844 Table 1 Contact angle measurement of the mPE before and after $\mathrm{HNO}_{3}$ treatment.

\begin{tabular}{lcc}
\hline S. & Sample & Average \\
No & & contact angle \\
\hline
\end{tabular}




\begin{tabular}{ccc}
\hline & & in degrees* $^{*}$ \\
\hline $\mathbf{1}$ & Untreated mPE & $86.06 \pm 1.15$ \\
$\mathbf{2}$ & $\mathrm{mPE}$ treated with & $72.03 \pm 2.05$ \\
& $\mathrm{HNO}_{3}(30$ minutes $)$ & \\
$\mathbf{3}$ & $\mathrm{mPE}$ treated with & $69.73 \pm 1.41$ \\
& $\mathrm{HNO}_{3}(60$ minutes $)$ & \\
\hline
\end{tabular}

846

847

848

849 Table 2 Tensile testing result of untreated, 30 minutes and 60 minutes $\mathrm{HNO}_{3}$ treated mPE.

850

\begin{tabular}{cccccc}
\hline S. & Sample & E-Modulus & Fmax. N & E-FMax.\% & W up to \\
No & & MPa & & & Fmax.Nmm \\
& & & & & \\
\hline $\mathbf{1}$ & Untreated mPE & 31.32 & 119.09 & 2510.82 & 30680.25 \\
$\mathbf{2}$ & mPE treated with & 33.01 & 120.63 & 2510.40 & 31114.00 \\
& $\mathrm{HNO}_{3}$ (30 minutes) & & & & \\
$\mathbf{3}$ & $\mathrm{mPE}$ treated with & 34.75 & 121.85 & 2510.39 & 32513.68 \\
\hline
\end{tabular}

851

852

853

854

855 


\section{1}

Schematic representation of series of characterization and blood compatibility experiments done

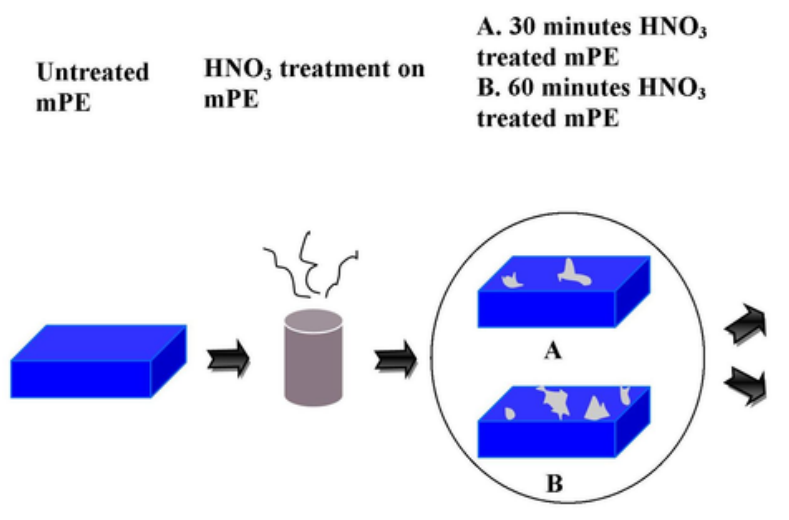

Characterization tests

Blood coagulation assays

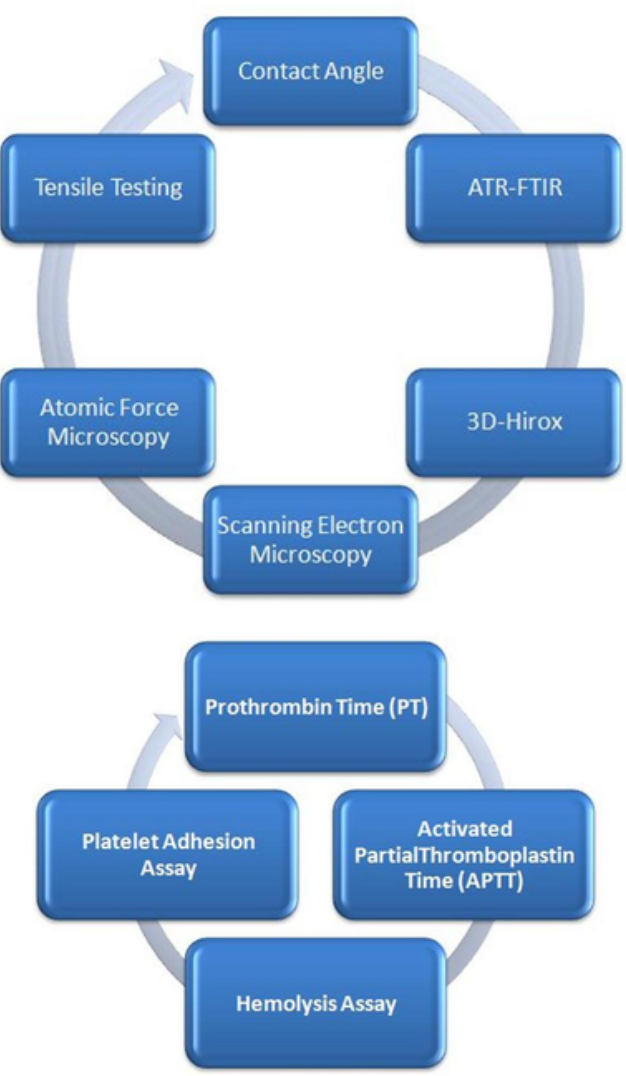


2

A representative FTIR spectra of untreated and $\mathrm{HNO} 3$ treated $\mathrm{mPE}$.

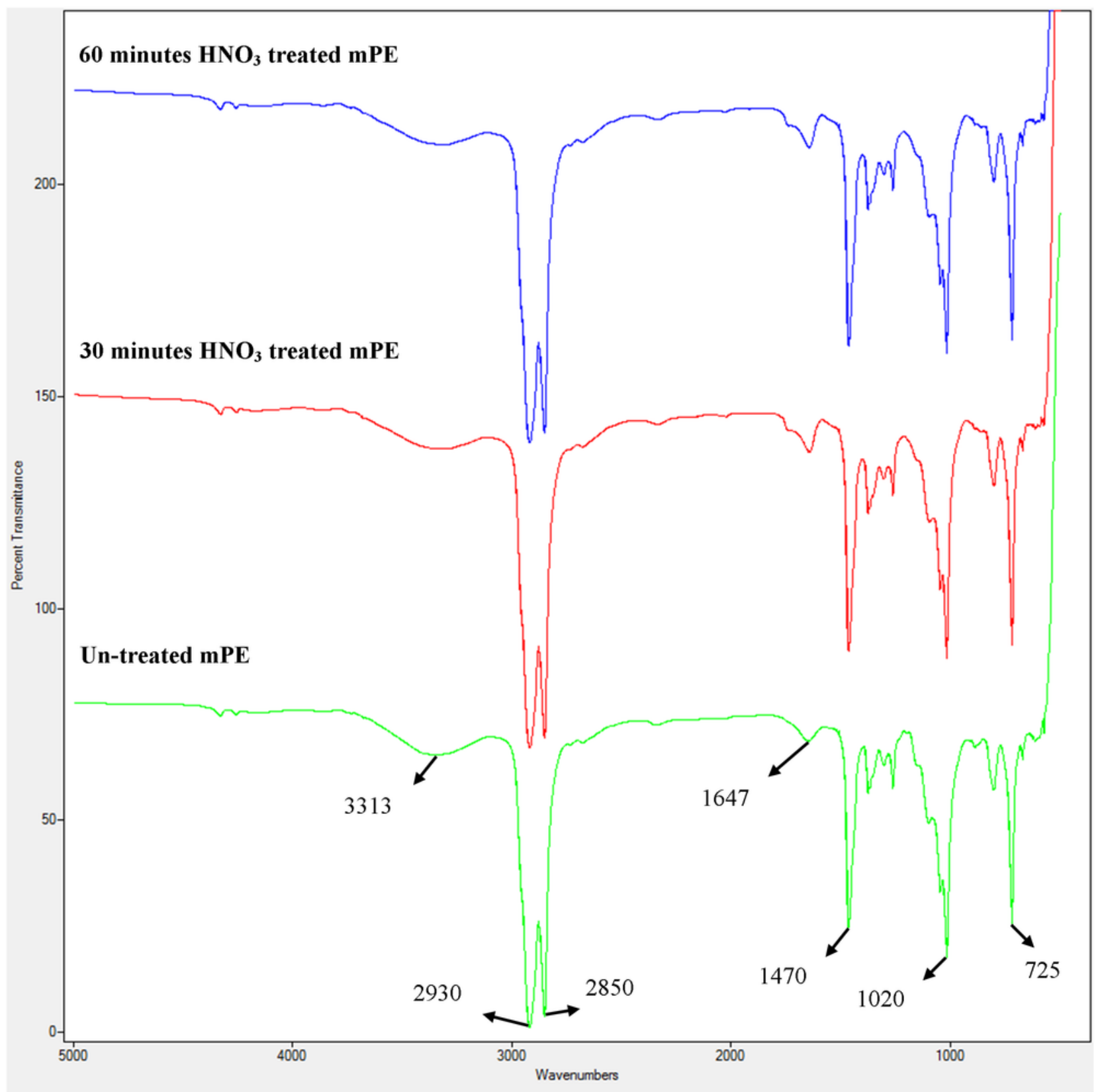


3

Different three-dimensional representations using 3D Hirox digital microscopy.

(A) Untreated mPE (B) Untreated mPE with profiling (C) 30 minutes HNO3 treated mPE (D) 30 minutes HNO3 treated mPE with profiling (E) 60 minutes HNO3 treated mPE (F) 60 minutes HNO3 treated MPE with profiling. 


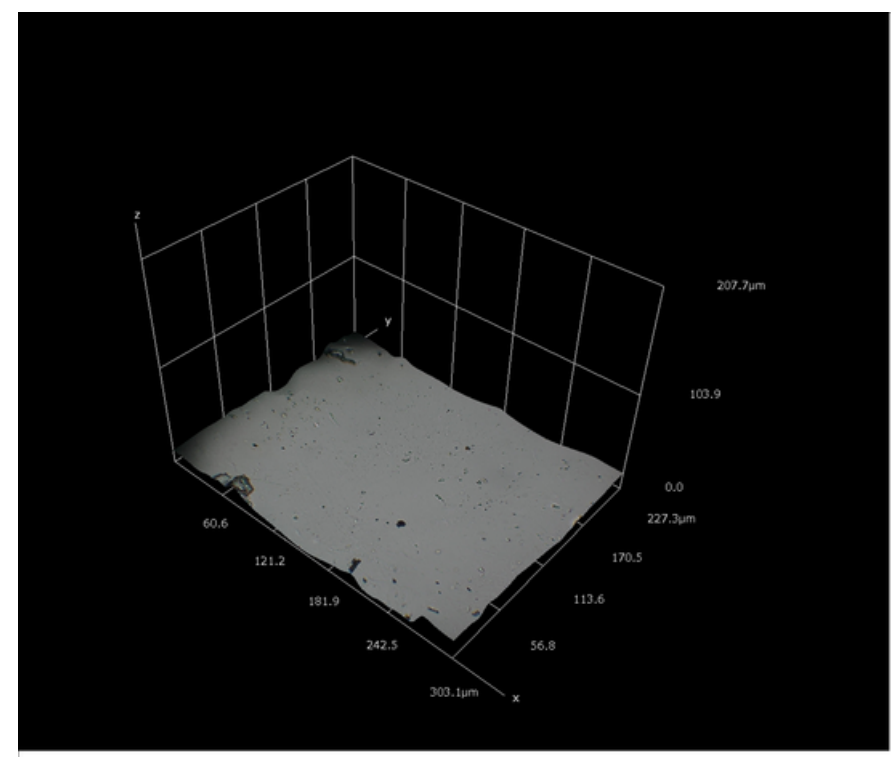

A

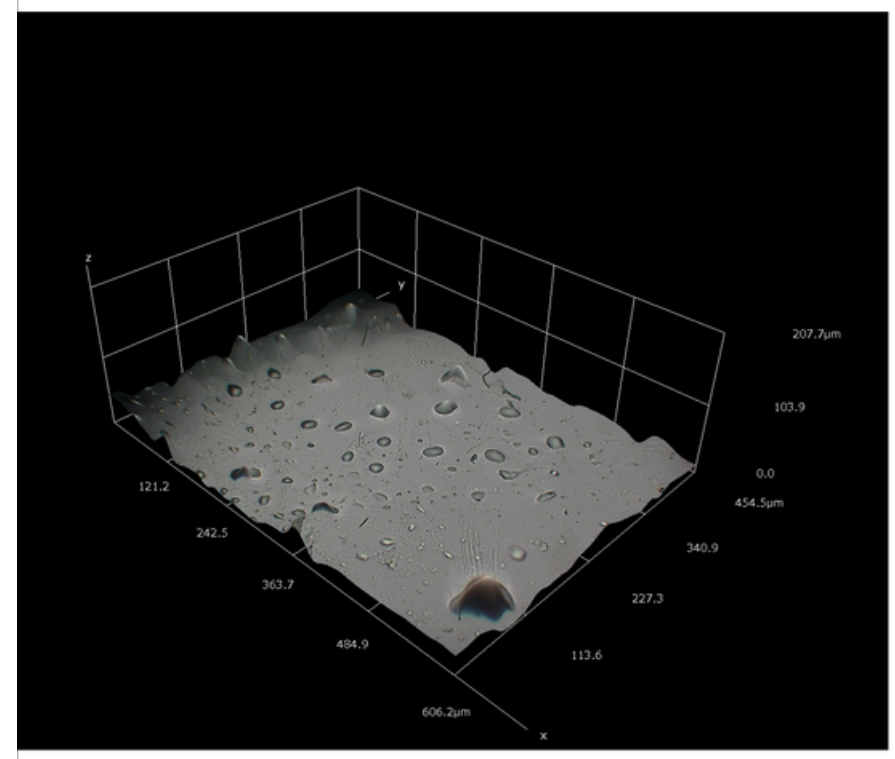

C

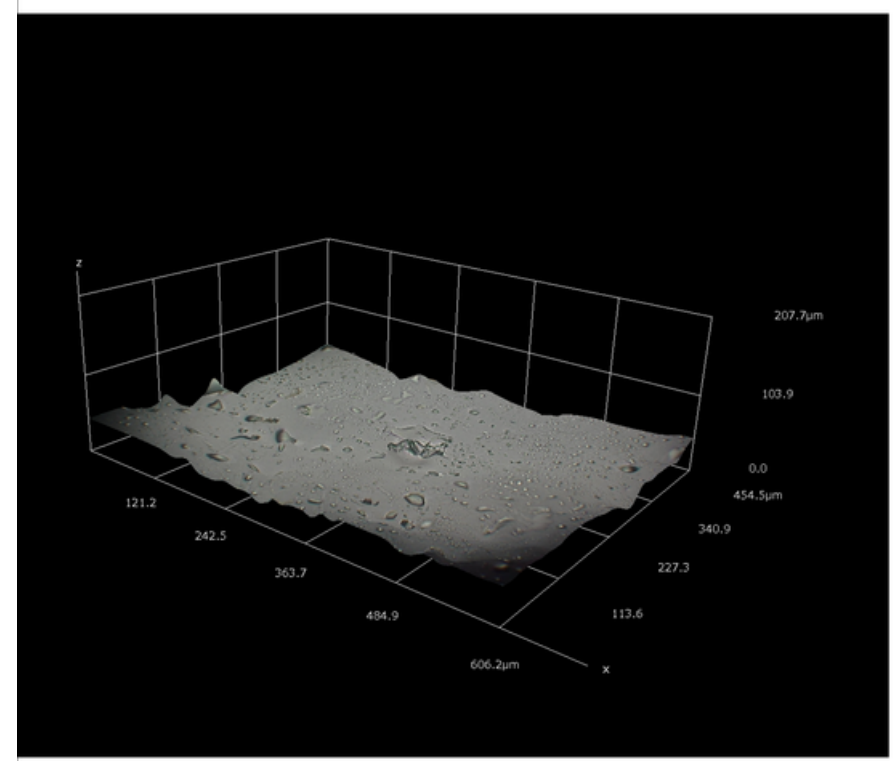

PeerJ reviewing PQE| (2015:07:5724:1:0:NEW 15 Oct 2015)

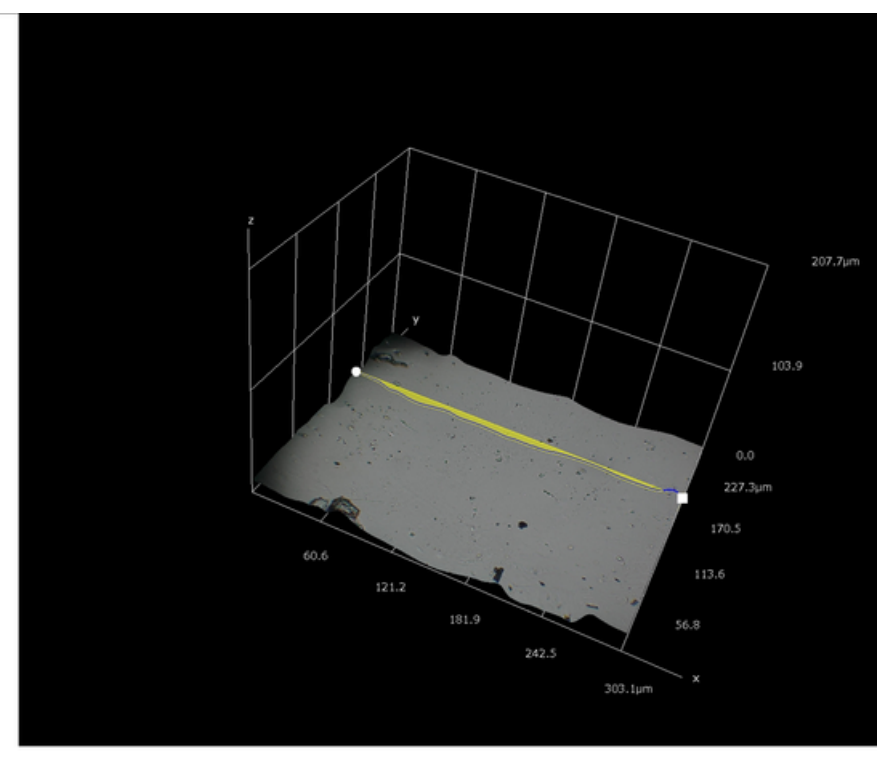

B

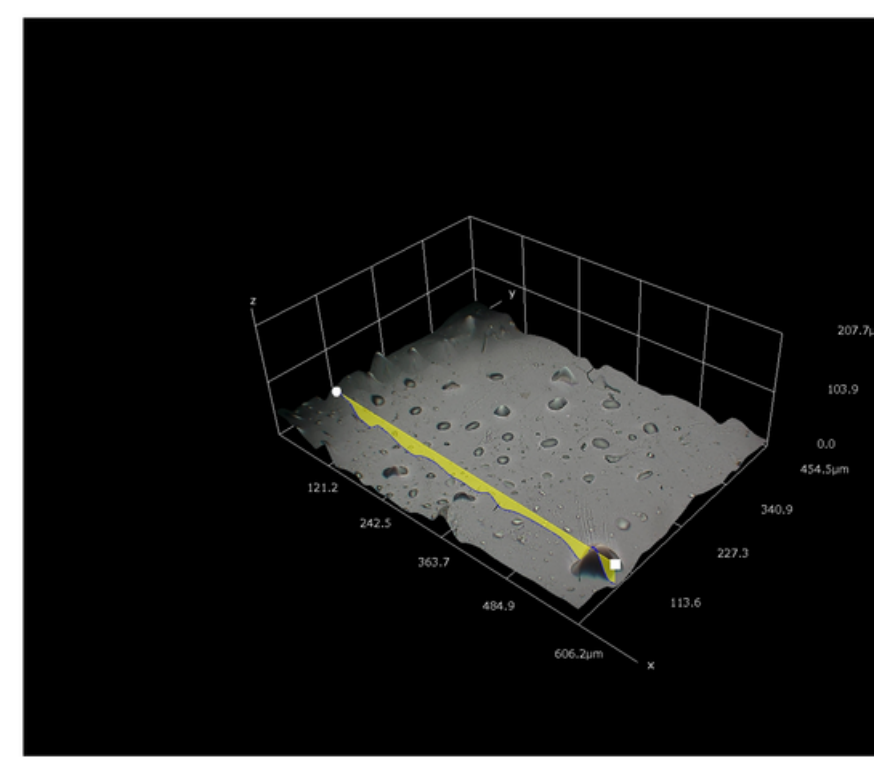

D

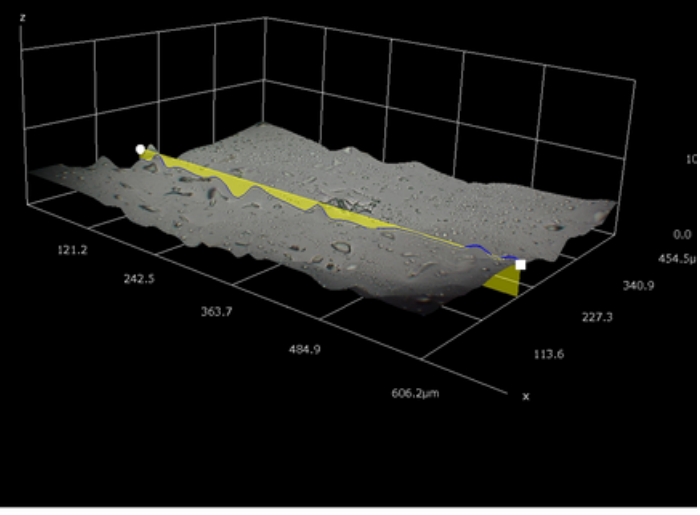


4

The representative height of the pores of different samples measured using 3D-profiling of 3D Hirox digital microscopy.

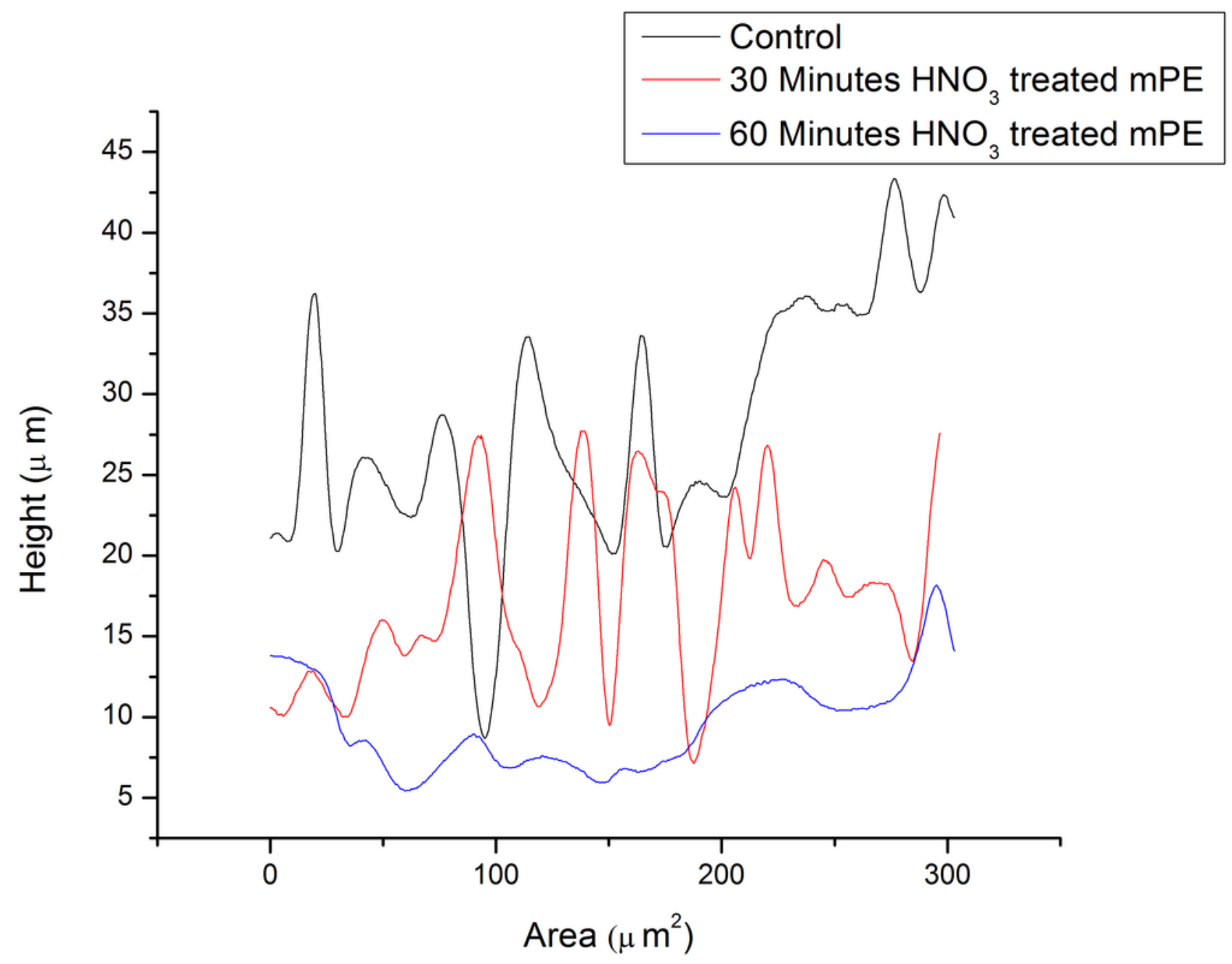




\section{5}

Representative SEM micrographs of untreated and HNO3 treated mPE.

(A) Untreated mPE (B) 30 minutes HNO3 treated mPE (C) 60 minutes HNO3 treated mPE.

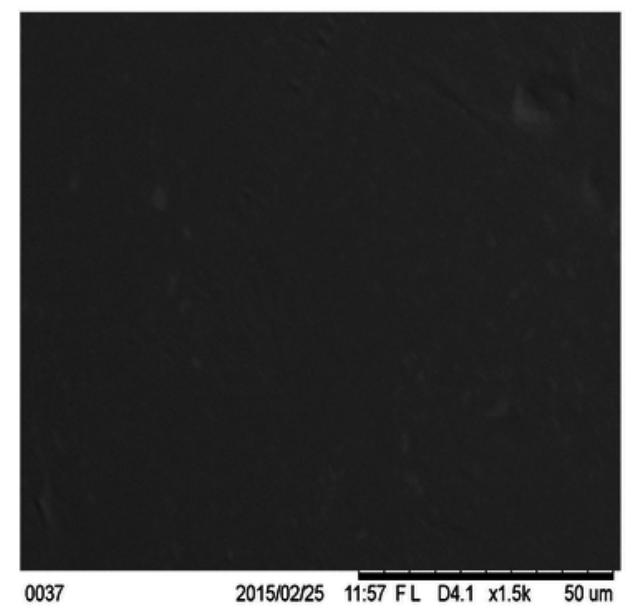

A

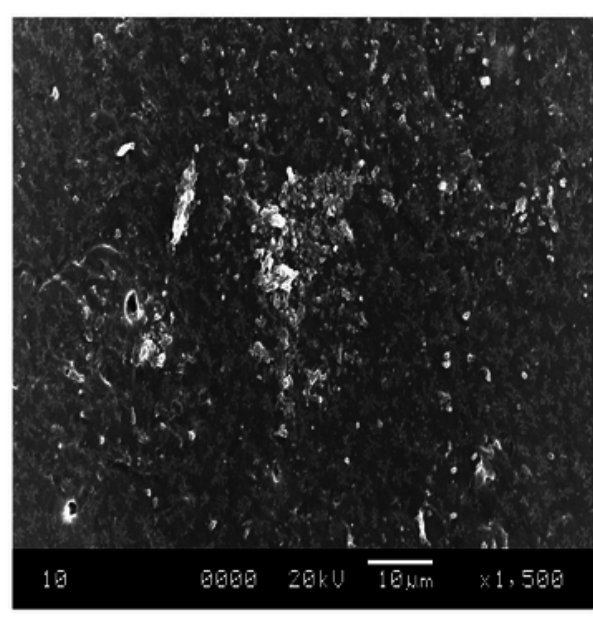

B

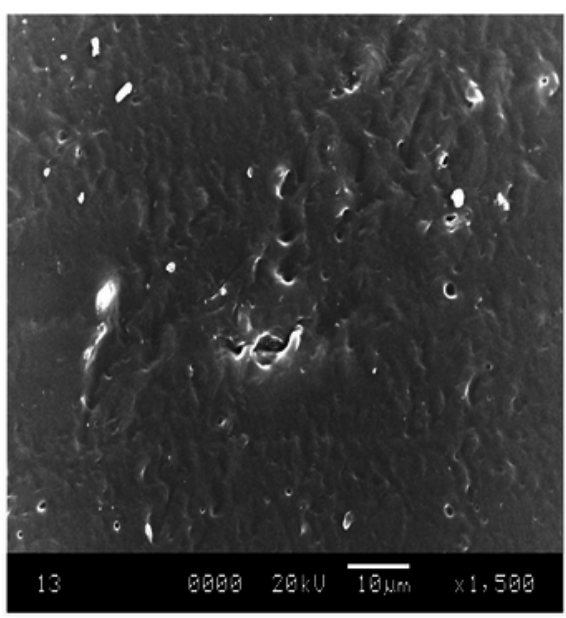

C 


\section{6}

Representative AFM images of untreated and HNO3 treated MPE.

(A) Untreated mPE (B) 30 minutes HNO3 treated mPE (C) 60 minutes HNO3 treated mPE

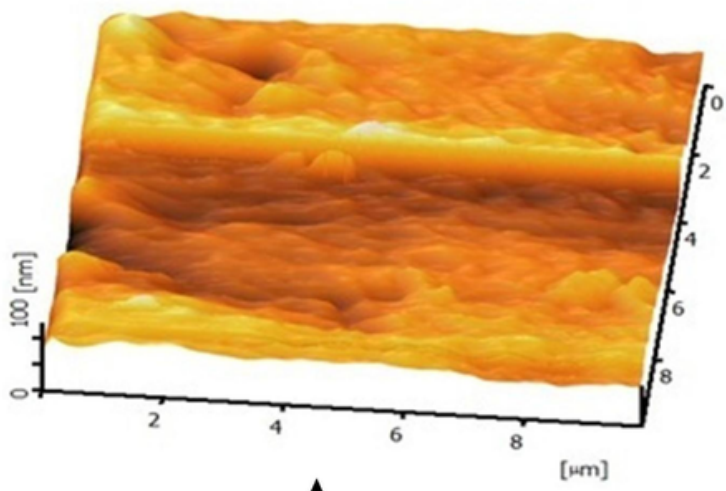

A
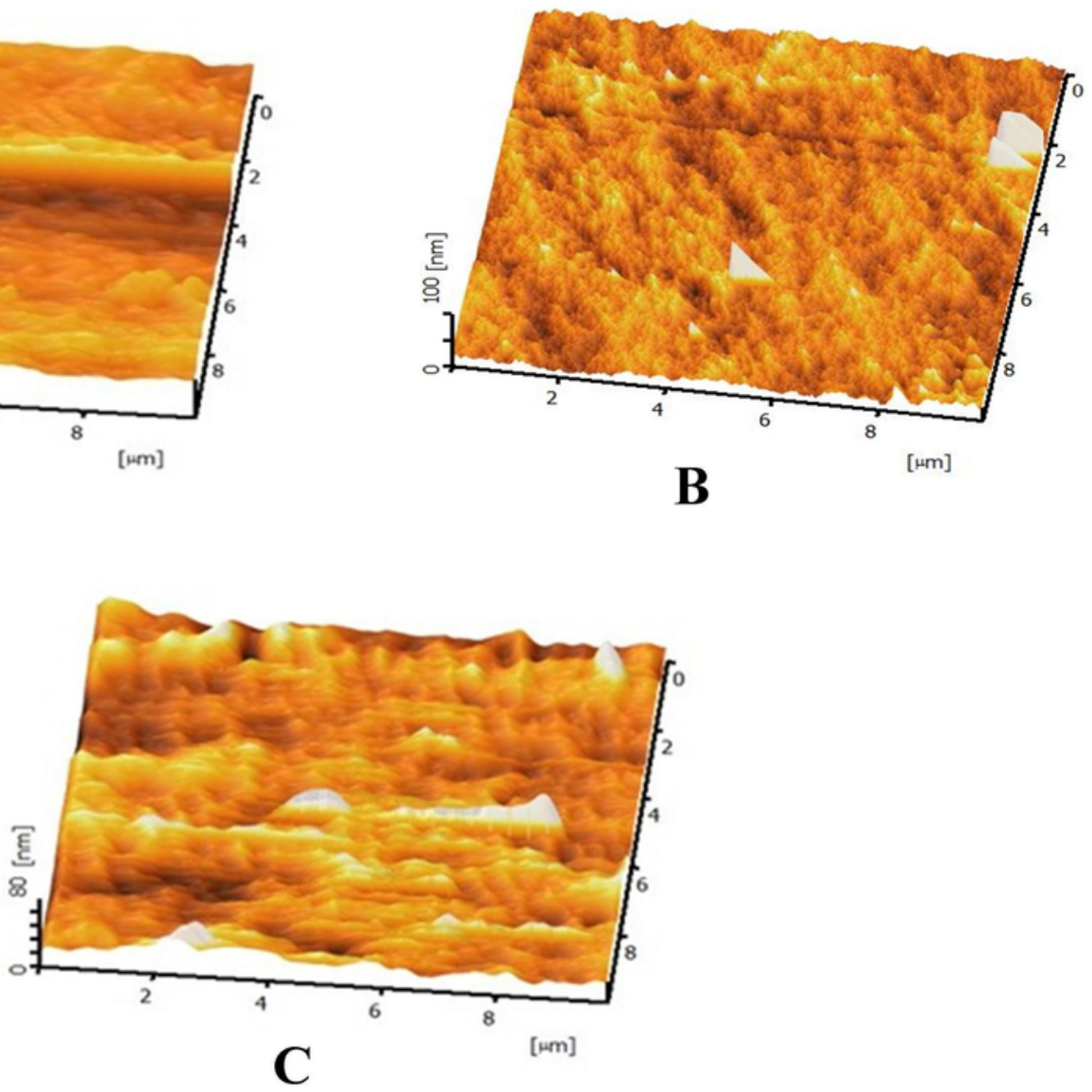
7

Representative tensile testing result of untreated and HNO3 treated MPE.

\section{(A) Untreated mPE (B) 30 minutes HNO3 treated mPE (C) 60 minutes HNO3 treated} MPE.

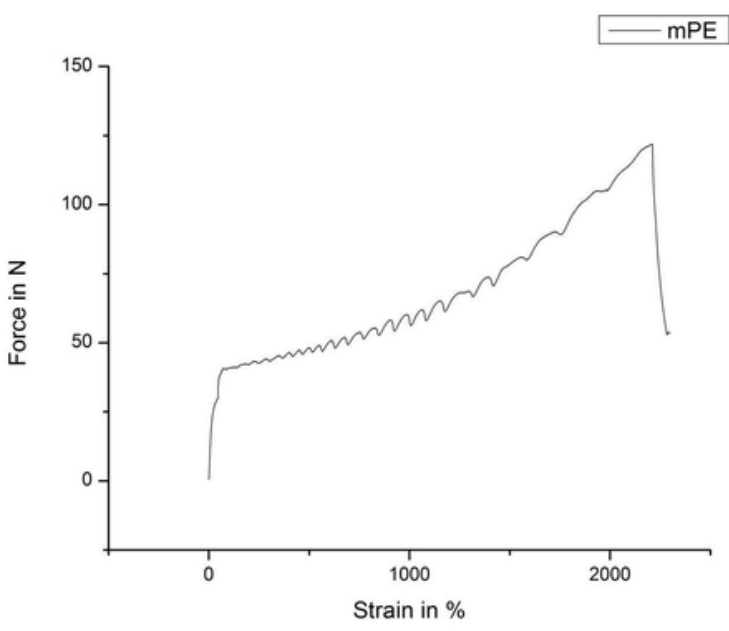

A
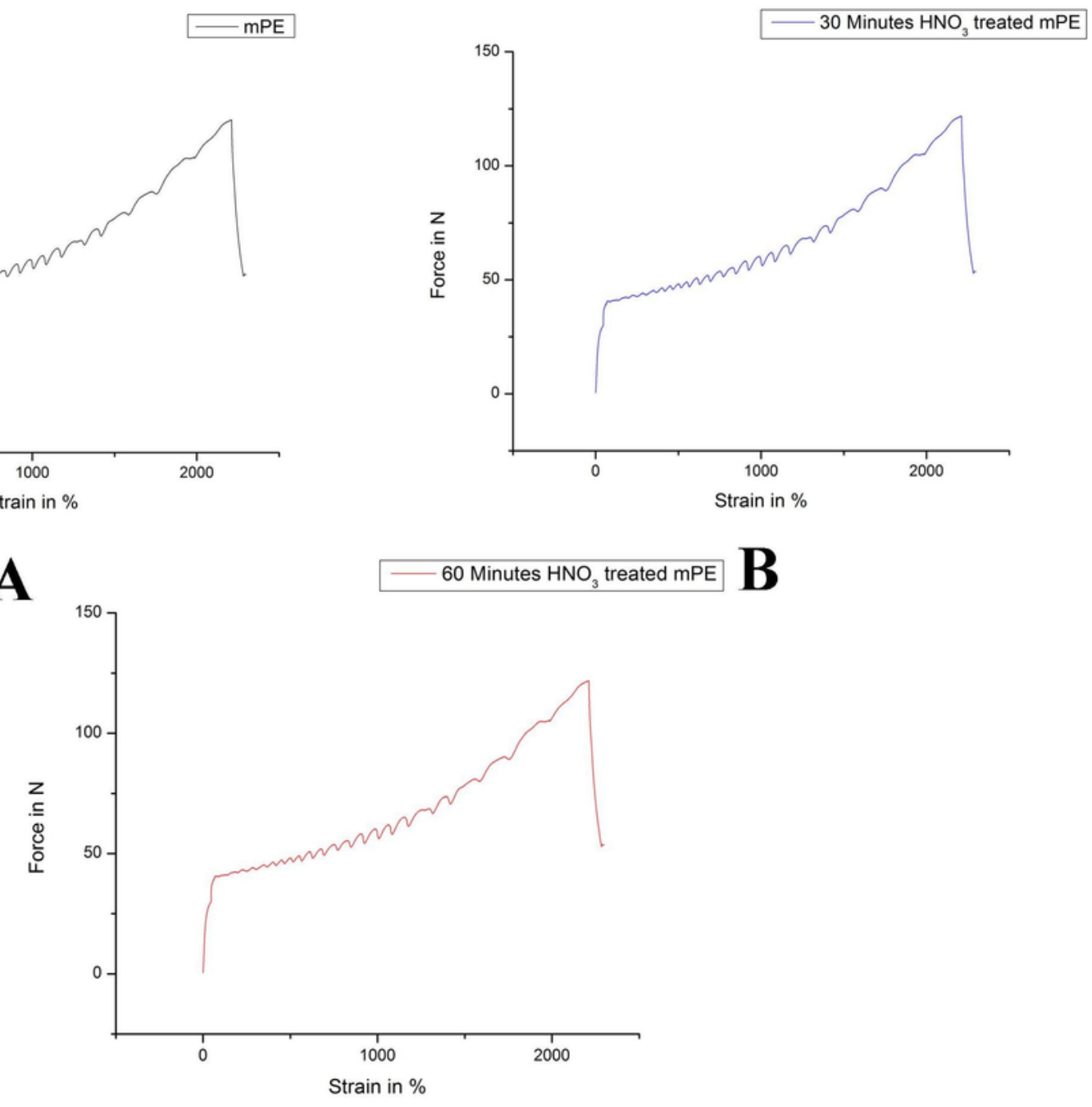

C 
8

Comparison of prothrombin time (PT), activated partial thromboplastin time (APPT) and absorbance of untreated and $\mathrm{HNO} 3$ treated $\mathrm{mPE}$.

(A) The PT of control, 30 minutes and 60 minutes HNO3 treated mPE (

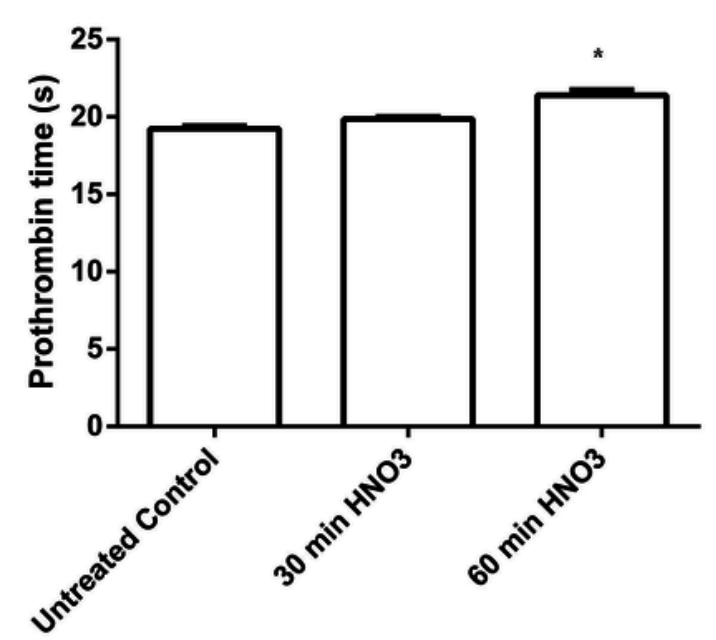

Duration of treatment (min)

A

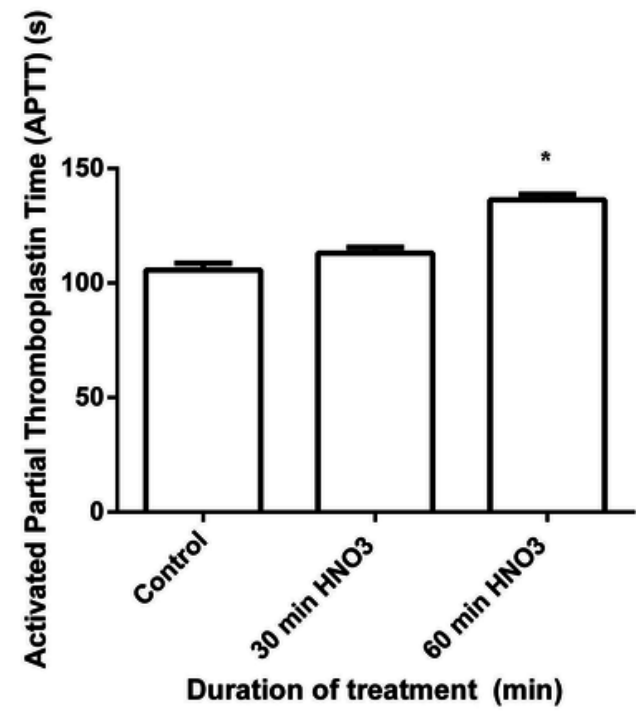

B

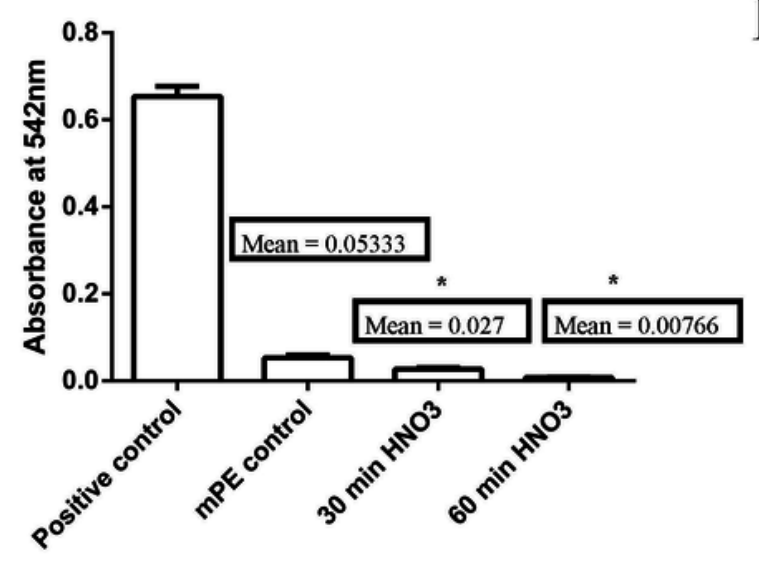

Duration of treatment (min)

C 
9

Platelet adhesion assay of untreated and $\mathrm{HNO}$ treated mPE.

(A) Comparison of the number of platelets adhered untreated, 30 minutes and 60 minutes HNO3 treated $\mathrm{mPE}$. Values are expressed as mean $\pm \mathrm{SD}$ and $*$ indicates difference in the means are significant with

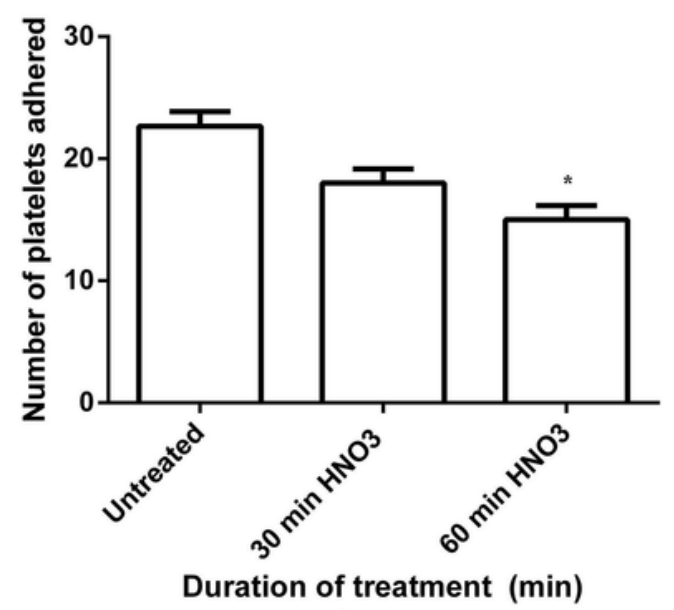

A

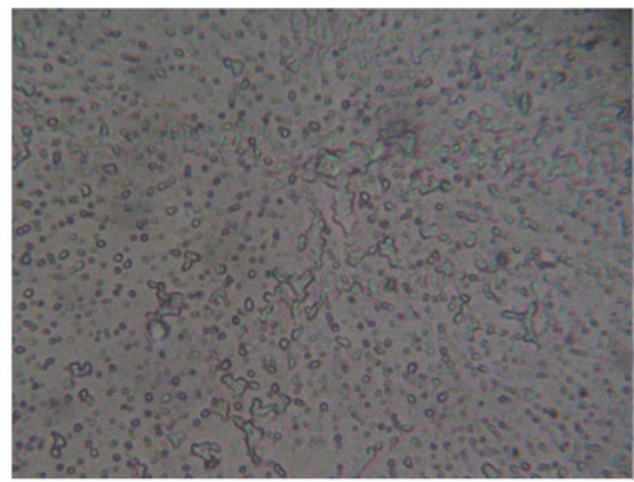

B

C

D 
10

Mechanism of improved hemocompatibility by $\mathrm{HNO} 3$ treatment. 

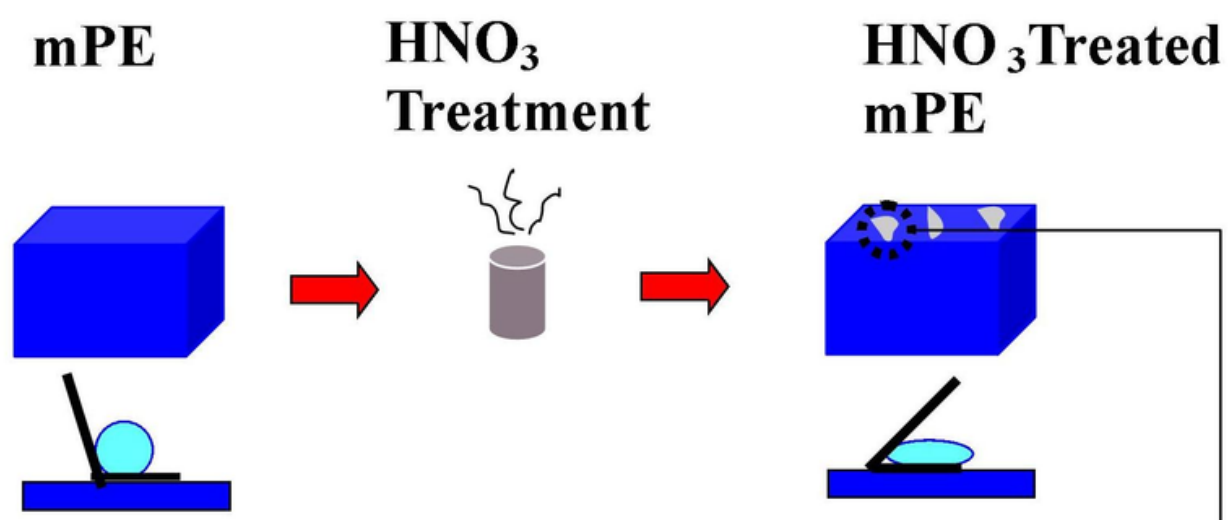

Improved Surface Roughness and Hydrophilicity

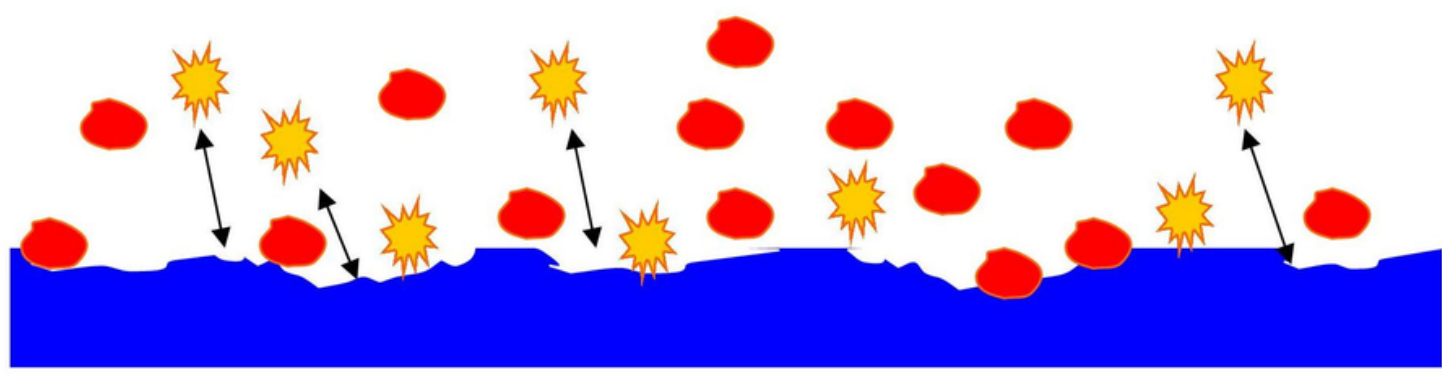

Water Droplet (Higher

Contact

Anlge)

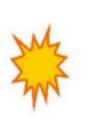

\section{Decreased \\ Platelet Adhesion}

Water Droplet

(Decreased

Contact

Angle)

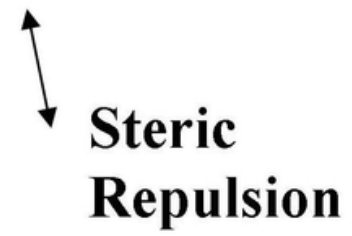




\section{Table 1 (on next page)}

Contact angle measurement of the MPE before and after $\mathrm{HNO}$ treatment. 
1 Table 1 Contact angle measurement of the mPE before and after $\mathrm{HNO}_{3}$ treatment.

2

\begin{tabular}{ccc}
\hline $\begin{array}{c}\text { S. } \\
\text { No }\end{array}$ & Sample & $\begin{array}{c}\text { Average } \\
\text { contact angle } \\
\text { in degrees* }\end{array}$ \\
\hline $\mathbf{1}$ & Untreated mPE & $86.06 \pm 1.15$ \\
$\mathbf{2}$ & $\mathrm{mPE}$ treated with & $72.03 \pm 2.05$ \\
& $\mathrm{HNO}_{3}$ (30 minutes) & \\
$\mathbf{3}$ & $\mathrm{mPE}$ treated with & $69.73 \pm 1.41$ \\
& $\mathrm{HNO}_{3}(60$ minutes $)$ & \\
\hline
\end{tabular}

3

4

5

6

7

8 


\section{Table 2(on next page)}

Tensile testing result of untreated, 30 minutes and 60 minutes $\mathrm{HNO} 3$ treated mPE. 
1 Table 2 Tensile testing result of untreated, 30 minutes and 60 minutes $\mathrm{HNO}_{3}$ treated mPE.

2

\begin{tabular}{|c|c|c|c|c|c|}
\hline $\begin{array}{l}\text { S. } \\
\text { No }\end{array}$ & Sample & $\begin{array}{c}\text { E-Modulus } \\
\text { MPa }\end{array}$ & Fmax. N & E-FMax.\% & $\begin{array}{c}\text { W up to } \\
\text { Fmax.Nmm }\end{array}$ \\
\hline 1 & Untreated $\mathrm{mPE}$ & 31.32 & 119.09 & 2510.82 & 30680.25 \\
\hline 2 & $\mathrm{mPE}$ treated with & 33.01 & 120.63 & 2510.40 & 31114.00 \\
\hline & $\mathrm{HNO}_{3}$ (30 minutes) & & & & \\
\hline 3 & $\begin{array}{c}\text { mPE treated with } \\
\mathrm{HNO}_{3} \text { (60 minutes) }\end{array}$ & 34.75 & 121.85 & 2510.39 & 32513.68 \\
\hline
\end{tabular}

3

4 